\title{
Stoffwechselmerkmale der Tumorzellen als Ziel komplementärer Therapien
}

\section{Metabolic Hallmarks of Tumor Cells as Target for Complementary Therapies}

\section{()(1) $(8)$}

Autoren

John lonescu ${ }^{1}$, Claus Schulte-Uebbing ${ }^{2}$, Peter Jennrich ${ }^{3}$

Institute

1 Spezialklinik Neukirchen, Bayern

2 Praxis für Frauenheilkunde, München

3 Praxis für Umweltmedizin, Würzburg

\section{Schlüsselwörter}

Krebs, Tumorstoffwechsel, Schwermetalle, Freie Radikale (ROS), Oxidose/Redose, Azidose/Alkalose, aerobe Glykolyse, $\mathrm{Na}^{+} / \mathrm{H}^{+}$Antiporter System, Carboanhydrasen, Hyperthermie, Vitamin C, Natriumbikarbonat, Polyphenole, ketogene Diät, glykämischer Index, Glykolyse-Inhibitoren, komplementäre Krebstherapien

\section{Key words}

cancer, tumor metabolism, heavy metals, free radicals, oxidosis/redosis, acidosis/alkalosis, aerobic glycolysis, $\mathrm{Na}^{+} / \mathrm{H}^{+}$ antiporter systems, carbonic anhydrases, hyperthermia, vitamin C, Na bicarbonate, polyphenols, ketogenic diet, glycemic index, glycolysis inhibitors, complementary cancer therapy

\section{Bibliografie}

DOI https://doi.org/10.1055/a-0582-4624

Deutsche Zeitschrift für Onkologie 2018; 50: 108-119

(c) Georg Thieme Verlag KG Stuttgart · New York

ISSN 1617-5891

Korrespondenzadresse

Assoc. Prof. (UMF) Dr. John lonescu

Spezialklinik Neukirchen

Krankenhausstraße 9

93453 Neukirchen

info@spezialklinik-neukirchen.de

\section{ZUSAMMENFASSUNG}

Eine kausale Verbindung zwischen der steigenden Umweltbelastung (Dieselpartikel, Schwermetalle, Pestizide, Phthalate, Lösungsmittel, Holzschutzmittel, Tabakrauch etc.) und der stetige Anstieg der Krebserkrankungen wird in den letzten Jahren registriert. Um die Zusammenhänge mit malignen Wachstumsprozessen beim Menschen zu erschließen, wurde die
Akkumulation von Metallen, Übergangsmetallen und Aluminium in Brustgewebsbiospien von gesunden Menschen und von onkologischen Patienten untersucht. Die Ergebnisse weisen erstmalig darauf hin, dass bei den Tumorbiopsien eine hochsignifikante Akkumulation von Eisen, Nickel, Chrom, Zink, Cadmium, Quecksilber, Blei und Aluminium im Vergleich zur Kontrollgruppe stattgefunden hat.

Die synergistische prooxidative Wirkung der Schwermetalle und anderer Umweltgifte im Tumorgewebe führt langfristig zur Hemmung der Energieproduktion in den Mitochondrien, verbunden mit einer adaptiven Verschiebung in Richtung Glykolyse und einer intrazellulären Akkumulation reduktiver Äquivalente (Glutathion, NADH, Cystein, Glukose) mit protektiver Wirkung gegen Chemo- und Radiotherapien.

In Einklang mit der vorhandenen Redose findet man eine permanente intrazelluläre Alkalisierung ( $\mathrm{pHi} 7,12-7,65)$ gegenüber Normalzellen (pHi 6,99-7,20), verbunden mit einer Aktivierung des HIF-1 Transkriptionsfaktors und der aeroben Glykolyse, die schon in den 30er Jahren als Warburg-Effekt beschrieben wurde. Die dauerhafte intrazelluläre Alkalisierung proliferierender Krebszellen ist weitgehend auf eine Aktivierung mehrerer Protonenpumpen, des MCT Laktat-Transporters und der Zn-abhängigen Carboanhydrasen zurückzuführen.

Die ununterbrochene Ausleitung der Protonen $\left(\mathrm{H}^{+}\right)$und des Laktats in den extrazellulären Raum sorgen für ein deutlich säuerliches Milieu im Tumorgewebe (pHe 6,2-6,9) im Vergleich zu normalem Gewebe (pHe 7,3-7,4), welches sowohl das Tumorwachstum als auch die Metastasierung eindeutig fördert und die Tätigkeit immunkompetenter Zellen blockiert.

Die Berücksichtigung der o.g. molekularbiologischen Merkmale gewinnt eine besondere Bedeutung in der Diagnose und Behandlung therapieresistenter neoplastischer Erkrankungen. Hierzu gehören neue integrative Therapieansätze mit einer signifikanten antiproliferativen und pro-apoptotischen Wirkung wie (1) die intravenöse Gabe von hochdosiertem Vitamin $\mathrm{C}$ und Polyphenolen mit Bildung höher ROS-Konzentrationen in situ, (2) die deutliche Reduzierung der Schwermetallkonzentrationen mittels spezifischer Chelatoren, (3) die Ausschaltung der intrazellulären Redose mit Hilfe prooxidativer Ansätze, (4) der Einsatz basischer Lösungen zur Pufferung der extrazellulären Azidose, (5) der Einsatz von Protonenpumpeninhibito- 
ren, zusätzlich zum Hemmer des $\mathrm{Na}^{+} / \mathrm{H}^{+}$Antiporter Systemen und der Carboanhydrasen, (6) die Auswahl einer entsprechenden Ernährungsform mit niedrigem glykämischen Index und ketogenen bzw. pro-oxidativen Eigenschaften, (7) die Hemmung der aeroben Glykolyse mit Hilfe spezifischer Enzyminhibitoren.

Die personalisierte Auswahl und Anwendung der o.g. integrativen Therapieformen abhängig vom Tumorstadium und metabolischem Tumortyp bietet eine wertwolle Ergänzung klassischer Therapien und ist weitgehend frei von Nebenwirkungen.

\section{ABSTRACT}

In recent years, a causal link between the increasing environmental pollution (diesel exhaust, pesticides, wood preservatives, phthalates, solvents, tobacco smoke, alcohol, heavy metals, preservatives, dyes, etc.) and a continuous increase in cancer incidence is registered. In order to explore the connection between environment and cancer growth in humans, we measured the accumulation of transitional metals and aluminum in breast biopsies from healthy women and breast cancer patients. Our results show for the first time a highly significant accumulation of iron, nickel, chrome, zinc, cadmium, mercury, lead and aluminum in the tumor biopsies, when compared to the control group. The synergistic pro-oxidative effect of various environmental toxins leads in the long term to the inhibition of cellular energy production in the mitochondria, combined with an adaptive shift towards aerobic glycolysis (Warburg effect) and an accumulation of reductive equivalents (glutathione, NADH, cysteine, glucose) with protective activity against chemo- and radiotherapies.
Consistent with their redosis state, proliferating cancer cells show a permanent intracellular alkalinization ( $\mathrm{pHi} 7.12-7.65)$ when compared to normal cells ( $\mathrm{pHi}$ 6.99-7.20), related to an activation of the transcription factor HIF- 1 and aerobic glycolysis and due to the strong expression of several proton pumps, MCTLactate transporters and Zn-dependent carbonic anhydrases.

The continuous excretion of $\mathrm{H}^{+}$and lactate in the extracellular space leads to a significant acidification of the tumor environment ( $\mathrm{pHe}$ 6.2-6.9) when compared to normal tissue (pHe 7.37.4). This fact is promoting the tumor growth, metastatic spreading and the inhibition of immune competent cells.

The above-mentioned molecular-biological markers gain an important role in the diagnosis and treatment of therapy-resistant neoplastic disorders. In this respect, new approaches with significant antiproliferative and pro-apoptotic effects include: (1) the use of high-dose intravenous vitamin $C$ and polyphenolic compounds leading in situ to high ROS concentrations, (2) the removal of the heavy metal burden with specific chelating agents, (3) the elimination of intracellular redosis by means of pro-oxidative approaches, (4) the use of basic solutions for buffering of the extracellular acidosis, (5) pharmacologic inhibition of proton-pumps, of $\mathrm{Na}^{+} / \mathrm{H}^{+}$antiport system and carbonic anhydrases, (6) the choice of an appropriate diet with low glycemic index, and high pro-oxidative ketogenic properties, and (7) the inhibition of key enzymes of aerobic glycolysis.

The described integrative therapies, mostly free of side effects, should be chosen in respect to the tumor stage and metabolic type. When used individually or in combination with classical oncologic approaches, they can lead to a considerable increase in patient's life expectancy and life quality.
Eine aktuelle Prognose betreffend die weltweite Prävalenz der Krebserkrankungen geht von einer 70 \%igen Erhöhung der Fallzahlen für die nächsten zwei Dekaden aus [151]. Diese Entwicklung ist einerseits an Umwelt-, Ernährungs- und Lifestyle-Faktoren gekoppelt und anderseits an die spärliche Anwendung von Therapien, die mehrere relevante Stoffwechselmerkmale der Krebszellen gleichzeitig berücksichtigen. Zu den Letzteren gehören signifikante Veränderungen der $\mathrm{pH}$-Werte und der Redox-Potentiale innerhalb und außerhalb der malignen Zellen, deren Energieversorgung durch die aerobe Glykolyse anstelle der oxidativen Phosphorylierung (OXPHOS), die Aktivierung der NADPH:Quinon-Oxidoreduktasen, der Ausfall bestimmter antioxidativer Enzymsystemen sowie die hohe Akkumulation von Übergangsmetallen und Organotoxine im Tumorgewebe.

\section{Metalle und Krebswachstum}

In den letzten Jahrzehnten wird über die Anwesenheit von Übergangsmetallen wie Eisen, Kupfer, Nickel oder Chrom im Zusammenhang mit der Produktion freier Radikale über Fenton/HaberWeiss Reaktionen, Autooxidation von Ascorbat, Peroxidationsprozessen von Fettsäuren und Bildung von DNA-Strangbrüchen berichtet $[7,85,92,123]$. Die durch Lipidperoxidation induzierten
Malondialdehyd-DNA-Addukte können sich wiederum in großer Menge im Brustgewebe von Frauen mit Brustkrebs anhäufen, verbunden mit endogenen DNA-Veränderungen [147] und Tumorbildung.

Da die Fähigkeit eines Eisen- oder Kupferüberschusses, Hydroxylradikale zu bilden, das zelluläre Immunsystem zu unterdrücken und Tumorwachstum zu fördern allgemein bekannt ist $[2,28,73,85,99,150]$, haben wir die Konzentrationen mehrerer Metalle und Übergangsmetalle in Brustkrebsbiopsien vom Institut für Onkologie und Pathophysiologie der Karls-Universität im Prag mit denen von Brustgewebe gesunder Frauen verglichen [55, 58].

Die Biopsien in der Patientengruppe wurden von Frauen im Alter von 23-49 Jahre gewonnen, die acht Kontorollbiopsien von gesunden Frauen im Alter von 21-43 Jahre wurden während Brustverkleinerungseingriffen im St. Josef Krankenhaus Regensburg entnommen. Die Ethikkommission der Karls-Universität Prag hat die Studie genehmigt, nachdem alle Teilnehmerinnen ihr schriftliches Einverständnis gegeben haben. Die histopathologischen Merkmale der untersuchten Tumoren sind in $\triangleright$ Tab. 1 beschrieben [55].

Keine Patientin wurde vor der OP chemotherapeutisch behandelt bzw. berufsbedingt Schwermetallen ausgesetzt. Allerdings waren alle Patientinnen durch Zahnmetalle wie Amalgamfüllungen, Goldbrücken, Metallimplantate oder Zahnspangen exponiert. 
- Tab. 1 Histopathologische Merkmale der untersuchten Brustkrebsbiopsien.

\begin{tabular}{|l|r|l|r|}
\hline Histologischer Typ & $\mathbf{n}$ & Stadium & $\mathbf{n}$ \\
\hline Duktales Karzinom & 12 & I & 5 \\
\hline Lobuläres Karzinom & 4 & II & 12 \\
\hline Andere & 4 & III & 1 \\
\hline & & unbekannt & 2 \\
\hline Hormonrezeptor-Status & $\mathbf{n}$ & HER2/neu Färbeintensität & $\mathbf{n}$ \\
\hline ER + & 13 & HERCEPTTEST 0 & 1 \\
\hline ER- & 7 & HERCEPTTEST 1 & 6 \\
\hline ER unbekannt & 0 & HERCEPTTEST 2 & 3 \\
\hline PR+ & 17 & HERCEPTTEST 3 & 3 \\
\hline PR- & 1 & ND * & 7 \\
\hline PR unbekannt & 2 & & \\
\hline
\end{tabular}

Eine andere bedeutsame Quelle ist Zigarettenrauch; etwa die Hälfte der Patientinnen waren Raucherinnen und fast alle waren durch Passivrauchen belastet.

Die Konzentration von Fe, Ni, Cr, Cu, Pb, Cd, Zn, Hg, Sn, Au, Pd in den Brustgewebeproben wurde in unserem Labor mit Hilfe einer standardisierten AAS-Technik mit Königswasser-Aufschluss zur Probenvorbereitung gemessen. Um systematische Fehler auszuschließen, wurde eine zweite Analysetechnik (ICP-MS) im Labor für Spurenelemente Hersbruck verwendet [58].

Die Datenanalyse zeigte eine signifikante Akkumulation von Eisen ( $p<0,0001)$, Nickel $(p<0,00005)$, Chrom ( $p<0,00005)$, Cadmium ( $p<0,005)$, Quecksilber $(p<0,005)$ und Zink $(p<0,001)$ im malignen Brustgewebe im Vergleich zu Kontrolluntersuchungen bei gesunden Probanden ( $\mathbf{A}$ bb. 1). Eine Vergleichsuntersuchung mit dem gesunden Brustgewebe derselben Personen war aus ethischen Gründen nicht möglich. Für die übrigen o.g. Metalle waren die Konzentrationsunterschiede nicht signifikant.

Ähnliche Ergebnisse wurden von uns auch anderweitig beschrieben $[127,128]$ und von unabhängigen Gruppen in nachfolgenden Studien bestätigt. Hierbei wurden in Biopsien von Tumorgewebe signifikant erhöhte Konzentrationen von Eisen, Aluminium, Chrom, Nickel und Zink im Vergleich zu benachbartem gesunden Gewebe oder Proben von Mammoplastien gefunden [29, 89, 90, 96].

\section{Eisen}

Das Eisen wird in der Blutbahn an Transferrin gebunden transportiert und wird von der Zelle durch das Bilden eines Komplexes zwischen dem eisenhaltigen Transferrin (Tf) und dem Transferrin-Rezeptor (TfR1) aufgenommen.

Proliferierende Zellen haben einen erhöhten Eisenbedarf, der durch die Anhäufung der TfR1auf der Zelloberfläche gedeckt wird. Normale Lymphozyten erhöhen die Dichte der TfR1 nach Stimulation mit mitogenen Faktoren um das 50-fache und lymphoide Zellen haben sogar die 1000-fache Zahl an Transferrin-Rezeptoren [68]. Im Einklang mit unseren Befunden [58, 127] weisen klinische Forschungsergebnisse eine deutlich höhere Transferrinrezeptoren- dichte sowie Ferritinanlagerung im Brustkrebsgewebe auf [31]. Des Weiteren führt ein Eisenmangel im Nährmedium zur Apoptose der Krebszellen [65]. Auch eine Überexpression der Zinktransportproteine ist in den Krebszellen gut dokumentiert [62, 71, 143].

Einmal in der Zelle aufgenommen, wird Eisen einerseits für die Synthese eisenhaltiger Enzyme benutzt, anderseits als Ferritinkomplex gespeichert.

Die hohe intrazelluläre Konzentration an Übergangsmetallen führt zu einer hohen ROS-Produktion via Haber-Weiss- und FentonReaktionen [58] (> Abb. 2) und kann neben anderen exogenen ROS-Quellen für die beträchtliche genetische Variabilität/Heterogenität der Tumorzellen, auch innerhalb des gleichen Tumors, verantwortlich sein $[26,39,144]$.

$$
\begin{aligned}
& \mathrm{OO}_{2}{ }^{-}+2 \mathrm{H}^{+} \stackrel{\mathrm{SOD}}{\longrightarrow} \mathrm{O}_{2}+\mathrm{H}_{2} \mathrm{O}_{2} \\
& \mathrm{H}_{2} \mathrm{O}_{2}+\mathrm{O}_{2}{ }^{-} \underset{\begin{array}{c}
\text { Haber-Weiss } \\
\text { Reaktion }
\end{array}}{\stackrel{\mathrm{Fe}^{3+}, \mathrm{Cu}^{2+}}{\longrightarrow}} \mathrm{HO}^{*}+\mathrm{HO}^{-}+\mathrm{O}_{2} \\
& \mathrm{Fe}^{2+}+\mathrm{H}_{2} \mathrm{O}_{2} \underset{\text { Fenton Reaktion }}{\stackrel{F^{3+}}{\text { Fen }}} \mathrm{HO}^{*}+\mathrm{HO}^{-}
\end{aligned}
$$

- Abb. 2 Bildung von Hydroxylradikalen im Rahmen der $\mathrm{H}_{2} \mathrm{O}_{2}$ - und metallabhängigen Fenton- und Haber-Weiss-Reaktionen.

Angesichts dieser Tatsachen erscheinen die geläufigen klinischen Verordnungen von Eisen- und Zinkpräparaten bei Krebspatienten eher kontraproduktiv, da in erster Linie die malignen Zellen damit versorgt werden.

Man sollte eigentlich versuchen dem Überschuss an Eisen entgegen zu wirken. Tatsächlich konnte das Binden des Eisens durch Chelatstoffe und das gleichzeitige Hemmen der Bildung des Tf-TfR1 Komplexes mittels eines monoklonalen Antikörpers das Tumorwachstum in einem Mausmodell wesentlich effizienter hemmen als jeder einzelner Stoff [63]. Erfreulicherweise belegen auch klinische Studien den Nutzen der Eisenchelatoren als Antikrebstherapie, u. a. gegen das Neuroblastom und die Leukämie [17, 114].

\section{Nickel, Chrom, Cadmium und Zink}

$\mathrm{Ni}, \mathrm{Cr}$ und $\mathrm{Cd}$ wurden aufgrund ihrer Fähigkeit, die Reparatur beschädigter DNA zu hemmen, als Mutagene und Karzinogene erkannt. Eine weitere ungünstige Eigenschaft ist ihre Fähigkeit, die Mutagenität und Karzinogenität direkt wirkender genotoxischer Stoffe zu erhöhen [13] sowie die proliferationssteigernde Wirkung aufgrund ihrer östrogenähnlichen Aktivität $[5,82]$, weshalb sie auch als „endokrine Disruptoren“ bezeichnet werden. Gleichzeitig wurden die karzinogenen Effekte von Ni, direkt oder im Zusammenspiel mit organischen Verbindungen, in der Literatur beschrieben $[48,97]$ und erhöhte Konzentrationen von Fe und Ni in malig- 


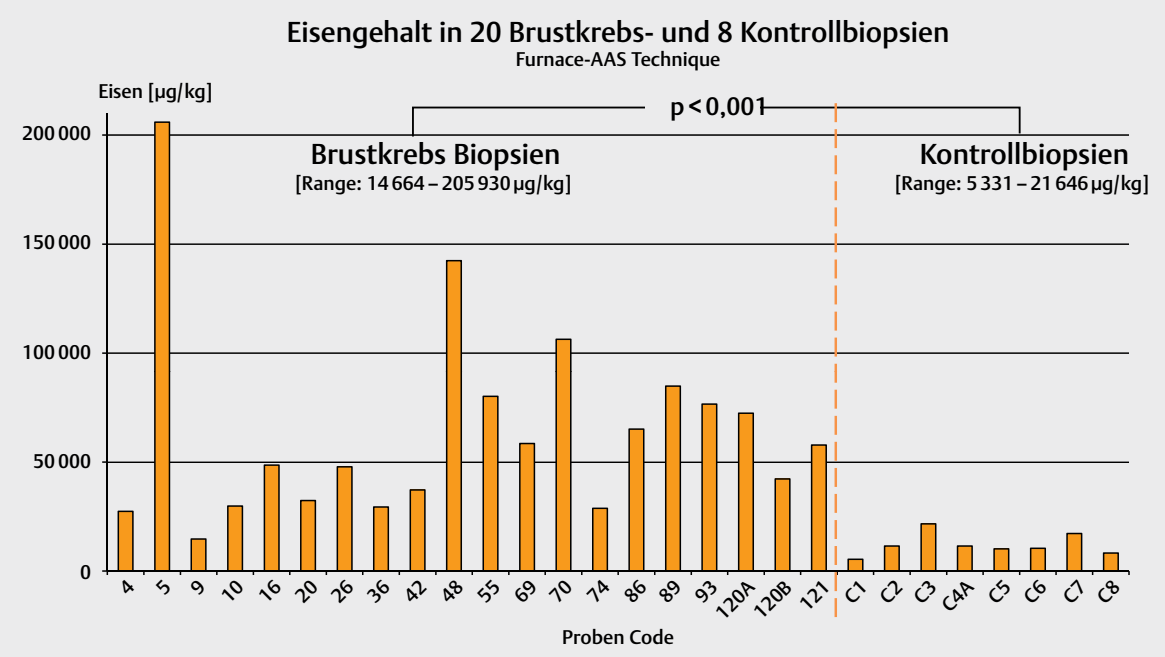

Nickelgehalt in 20 Brustkrebs- und 8 Kontrollbiopsien

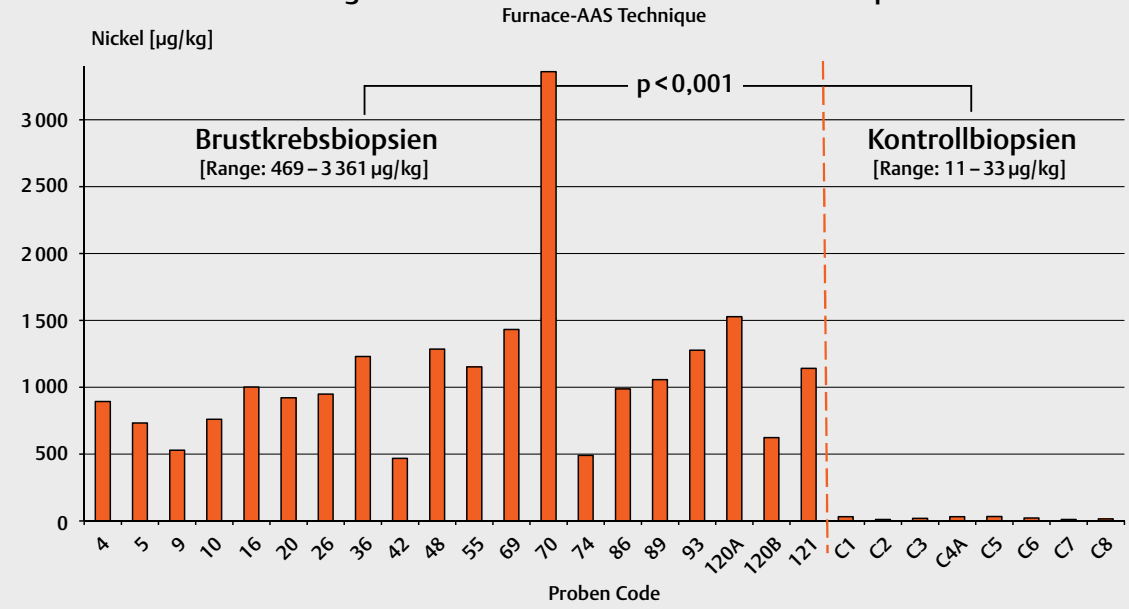

Proben Code

Zinkgehalt in 20 Brustkrebs- und 8 Kontrollbiopsien

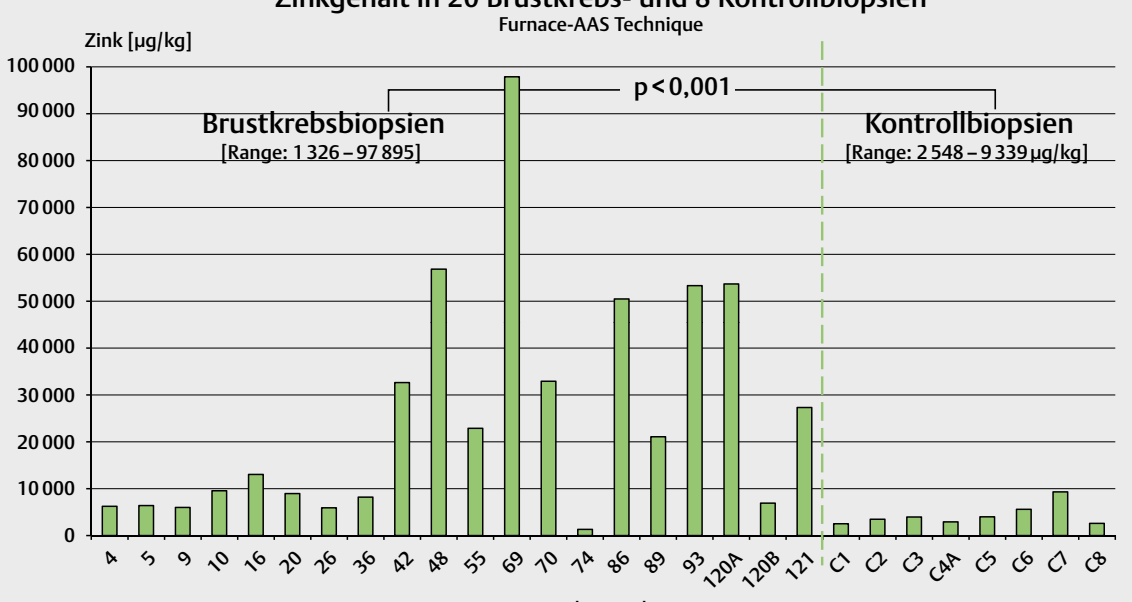

Proben Code

Abb. 1 Der Eisen-, Nickel- und Zinkgehalt der 20 Brustkrebsbiopsien ist bis zu 10-mal, 100-mal bzw. 25-mal höher als in den 8 Kontrollbiopsien [55].

nem menschlichem Prostatagewebe gefunden [152]. Die Inhalation bestimmter Formen von sechswertigem Chrom verursacht Lungenkrebs und auf zellulärer Ebene kann eine Chrombelastung zur Hemmung der Apoptose oder neoplastischen Veränderungen führen [134]. Die berufsbedingte Cadmiumexposition kann Lun- genkrebs verursachen und hohe Cadmiumkonzentrationen wurden in proliferativen Prostata-Läsionen gefunden [145].

Interessanterweise wurde gezeigt, dass Zink als notwendiges Spurenelement Tumorwachstum vermittelt und beschleunigt, während sich Zinkmangel bei Mäusen und Ratten als das Tumor- 
- Tab. 2 Akkumulation von Übergangsmetallen und Aluminium in Brustkrebsgewebe einer Patientin (V.N.M.) und deren Nachweis in Urin nach Mobilisation mit Chelatbildnern (AAS-Methode).

\begin{tabular}{|c|c|c|c|c|c|c|}
\hline \multirow{3}{*}{ Metall } & \multicolumn{3}{|c|}{$\begin{array}{l}\text { Tumorgewebe (Mamma-CA) } \\
\text { (V.N.M., } 59 \text { Jahre) }\end{array}$} & $\begin{array}{l}\text { Gesunde } \\
\text { Gewebe }\end{array}$ & \multicolumn{2}{|c|}{$\begin{array}{l}\text { Urin nach } \\
\text { DMPS + EDTA Mobilisation }\end{array}$} \\
\hline & \multicolumn{4}{|c|}{$\mu \mathrm{g} / \mathrm{kg}$ Gewebe } & \multicolumn{2}{|c|}{$\mu g / g$ Kreatinin in Urin } \\
\hline & Probe 1 & Probe 2 & Probe 3 & Normwert & nach Mobilisation & Normwert \\
\hline Quecksilber $(\mathrm{Hg})$ & $\uparrow 10,9$ & $\uparrow 20,1$ & $\uparrow 11,4$ & $<2,1$ & $\uparrow 137,5$ & $<50,0$ \\
\hline Zinn (Sn) & $<10,0$ & $<10,0$ & $<10,0$ & & $\uparrow \mathbf{4 , 4}$ & $<2,0$ \\
\hline Kupfer (Cu) & 951,3 & 687,3 & 737,3 & $<1565$ & 124,5 & $<500,0$ \\
\hline Cadmium (Cd) & $<5,0$ & $\uparrow 62,9$ & $\uparrow 37,8$ & $<16$ & $\uparrow 16,5$ & $<1,3$ \\
\hline Nickel (Ni) & 22,9 & $\uparrow 113,5$ & $\uparrow 132,7$ & $<21$ & $\uparrow \mathbf{5 , 0}$ & $<1,7$ \\
\hline Chrom (Cr) & 2,5 & $\uparrow 124,9$ & $\uparrow 182,8$ & $<39$ & $\uparrow \mathbf{2 , 5}$ & $<1,5$ \\
\hline Aluminium (Al) & $\uparrow 17480$ & $\uparrow 27170$ & $\uparrow 28910$ & $<12000$ & $\uparrow 158,6$ & $<40,0$ \\
\hline Eisen (Fe) & $\uparrow 42913$ & $\uparrow 75598$ & $\uparrow 82548$ & $<10937$ & $\uparrow \mathbf{8 6 6 , 0}$ & $<130,0$ \\
\hline
\end{tabular}

wachstums hemmend herausstellte [84, 91, 142]. Ebenfalls zeigten makromolekulare Komponenten (Dextrans), die mit Quecksilber-haltigen Seitenketten substituiert worden waren, beim Fibrosarkom von Mäusen eine wachstumsfördernde Wirkung [108].

Die Ätiologie der meisten Brusttumore beim Menschen wird immer noch kontrovers diskutiert. Wir haben argumentiert, dass Umweltschadstoffe, die oxidativen Stress und Lipidperoxidation verursachen, auch als endokrine Disruptoren eine Rolle bei der Entstehung von Brustkrebs spielen können $[60,126]$.

Eine chronisch-toxische Belastung mit Übergangsmetallen, verbunden mit genetischen Polymorphismen der Detox-Phase II-Konjugierungs-Enzyme sowie der Überexpression der Metall-Transportproteine oder deren Rezeptoren, können für dieses Phänomen verantwortlich sein [53].

Aufgrund des immer breiteren Kontakts mit Aluminiumverbindungen häufen sich die Hinweise betreffend einer Beteiligung des Leichtmetalls an Tumorentstehung und -wachstum aufgrund seiner mitochondrienschädigenden und östrogenähnlichen Wirkungen $[24,61,70]$.

\section{Merke}

Als Xeno-Östrogene bezeichnet man körperfremde Substanzen, die innerhalb der Körperzellen ähnlich wie die Östrogene wirken oder deren biologische Aktivität verändern.

Unter den Xeno-Östrogenen nehmen die Metallo-Östrogene eine besondere Rolle ein. Metallo-Östrogene sind kleine Metall- und Metalloid-Anionen sowie zweiwertige Kationen, wie z. B. Aluminium-, Cadmium-, Calcium-, Kobalt-, Kupfer-, Nickel-, Chrom-, Blei, Quecksilber- und Zinn-Ionen. Metallo-Östrogene aktivieren die Östrogen-Rezeptoren in Abwesenheit von Östradiol [18]. Dadurch kann die Exposition gegenüber diesen Metallen das Risiko erhöhen, an Brustkrebs zu erkranken [60].
Metallo-Östrogene lösen auch Veränderungen an den Östrogenbindungsstellen der Gene im Zellkern aus. In Brustdrüsenzellen führt dies zu einer Erhöhung der Zellteilung. Dadurch entstehen mehr Fehler bei der DNA-Vervielfältigung, was ein entsprechend erhöhtes Krebsrisiko zur Folge hat. Zellen, die bereits zu Brustkrebszellen entartet und östrogenrezeptor-positiv sind, werden durch die Metalle zum Wachstum angeregt [18].

Mehrere Arbeiten [24, 61, 70] sowie aktuelle Ergebnisse aus unserem Labor bestätigen die erhöhte Akkumulation von Aluminium und der oben erwähnten Übergangsmetalle in Brustkrebsbiopsien ( $\triangleright$ Tab. 2.)

Unsere Studien beschreiben erstmals eine erhebliche Akkumulation von Eisen und anderen Übergangsmetallen wie $\mathrm{Ni}, \mathrm{Cr}, \mathrm{Cd}$, $\mathrm{Zn}, \mathrm{Hg}$ und $\mathrm{Pb}$ sowie Aluminium im Brustkrebsgewebe mit möglichen Auswirkungen auf die Pathogenese der Erkrankung [58, 127]. Diese kann im Einzelfall jedoch nicht eindeutig verifiziert werden. Die Freisetzung der Metalle infolge einer therapeutischen Tumorzerstörung kann zu deren Umverteilung mit erheblichen toxischen und mutagenen Nebenwirkungen führen, mit negativen Folgen für die Progression der Erkrankung. Effektive Chelattherapien können hier einen positiven Detox-Beitrag leisten und zu einer schnelleren Erholung des Patienten führen, wie aus eigenen Erfahrungen beobachtet (s.u. - Abb. 5).

Eine weitere stoffwechselrelevante Folge der Metall- und Organotoxinspeicherung $[6,29,52]$ ist die Akkumulation reduktiver Äquivalente als adaptive Überlebensstrategie der Tumorzellen gegen oxydativen Stress $[11,18]$. Dies führt zu einer erheblichen Verschiebung des intrazellulären Redoxpotentials und pH in Richtung Redose bzw. Alkalose mit nachfolgenden Veränderungen des Tumorstoffwechsels. 


\section{Die Redoxpotential-Verschiebung in Tumorzellen}

Die Redox- und pH-Verschiebungen bezeichnen Elektronen- bzw. Protonen-Transferreaktionen in biologischen oder chemischen Systemen. Sie sind eng miteinander verbunden nach der Regel: je niedriger der $\mathrm{pH}$, desto höher das Redoxpotential (Eh) und je höher der $\mathrm{pH}$, desto niedriger das Redoxpotential. Die entsprechenden Abweichungen von der Norm in biologischen Systemen sind seit Jahrzenten unter den Begriffen Oxidose/Redose bzw. Azidose/Alkalose bekannt.

Shapiro [131] definiert die Redose als Akkumulation nichtflüchtiger reduktiver Äquivalente (wie z. B. Glutathion, $\mathrm{NADH}$, Cystein, Glukose), im Gegensatz zur Akkumulation oxidativer Stoffe $\left(\mathrm{O}_{2}, \mathrm{O}_{3}\right.$, Halogene, Metalle in oxidierter Form, Umweltschadstoffe etc.), die als Oxidose definiert wird.

Im Hintergrund der Redoxverschiebungen stehen respiratorische oder Stoffwechseleinflüsse, wobei körperliche Bewegung, Ernährung und Umweltfaktoren eine entscheidende Rolle spielen $[56,59]$. Die Messung der Redox-Potentiale in verschiedenen biologischen Proben kann potentiometrisch mithilfe entsprechender Elektroden in einer standardisierten Redox-Zelle $\left(37^{\circ} \mathrm{C}\right.$, Argon-Atmosphäre) erfolgen [56, 59]. Das Messergebnis im Blut, Plasma oder Gewebe (Eh in $\mathrm{mV}$ ) spiegelt die Summe aller Redoxpaare in der Probe wider, wobei in der Regel das Verhältnis zwischen dem reduzierten und oxidierten Glutathion (GSH/GSSG) und der $\mathrm{pO}_{2}$ maßgebend für den zellulären Redoxstatus sind [117].

In der Tat korrelieren die Eh-Verschiebungen des GSH/GSSG Paares mit dem biologischen Status normaler Zellen: -220 mV (Redose/Proliferation), -200 mV (Differenzierung), -170 mV (Oxidose/ Apoptose) [124], während proliferierende Krebszellen eine permanente Redose mit einer erhöhten Akkumulation von reduziertem Glutathion, NADH, NADPH, Cystein bzw. Glukose via GLUT/Transporter, aufweisen [25, 66, 79, 109, 153].

Als Ursachen dafür werden hypoxische Zustände sowie eine signifikante Anhäufung von elektrophilen organischen Noxen $[6,30,45]$ und Übergangsmetallen $[58,126,138]$ im entarteten Gewebe nach Ausfall der entsprechenden Detox- und antioxidativen Schutzsysteme (SOD, Katalase) $[104,119,122,129]$ verantwortlich gemacht.

Die erhöhte Glutathionsynthese der malignen Zellen wird als adaptive Antwort und Resistenzmechanismus gegen verschiedene pro-oxidative Angriffe (Akkumulation von Schwermetallen bzw. Organotoxinen, Chemotherapie, Bestrahlung, endogene ROS-Produktion) angesehen und mit deren Proliferationsneigung in Verbindung gebracht $[11,43,53,58,120,144]$.

\section{Intrazelluläre Alkalisierung der Tumorzellen}

$\mathrm{pH}$-Messungen in gesundem Gewebe unter normalen $\mathrm{pO}_{2}$-Werten assoziieren eine temporäre Growth Factor- induzierte Proliferation mit einer intrazellulären Alkalisierung und einer erhöhten aeroben
Glykolyse [12, 16, 148]. In Einklang mit der vorhandenen Redose weisen proliferierende Krebszellen eine permanente intrazelluläre Alkalisierung ( $\mathrm{pHi} 7,12-7,65)$ gegenüber Normalzellen ( $\mathrm{pHi}$ 6,99$7,20)$ auf $[21,42,112]$, verbunden mit einer starken aeroben Glykolyse, die schon in den 30er-Jahren als Warburg-Effekt beschrieben wurde [40, 103, 149].

Die dauerhafte intrazelluläre Alkalisierung proliferierender Krebszellen ist weitgehend auf eine Aktivierung des $\mathrm{Na}^{+} / \mathrm{H}^{+}$Antiporter Systems NHE1 $[34,135]$, der V-ATPase Protonen-Pumpe $[32,105,137]$ und des MCT Laktat-Transporters, die für eine ununterbrochene Ausleitung der Protonen $\left(\mathrm{H}^{+}\right)$und des Laktats im extrazellulären Raum sorgen, zurückzuführen [95] (\Abb. 3).

\section{Extrazelluläre Azidose im Tumorgewebe}

Eine Hypoxie- bzw. HIF1-bedingte Hyperexpression der membrangebundenen und zinkabhängigen Carboanhydrasen CA2, CA9 und CA12 wurde bereits in vielen Tumoren nachgewiesen $[49,139-$ 141] und ist zusammen mit Anion-Exchangers wie $\mathrm{Cl}^{-} / \mathrm{HCO}_{3}{ }^{-}$(AE1) in der Krankheitsprogression involviert $[94,136]$. Dementsprechend findet man ein deutlich säuerliches extrazelluläres Milieu im Tumorgewebe (pHe 6,2-6,9) im Vergleich mit normalem Gewebe ( $\mathrm{pHe} 7,3-7,4)$, welches das Tumorwachstum und die Metastasierung eindeutig fördert $[46,112]$ und die Tätigkeit immunkompetenter Zellen blockiert [37, 50].

\section{Aktivierung der aeroben Glykolyse (Warburg Effekt)}

Die erfolgte intrazelluläre $\mathrm{pH}$-Steigerung in malignen Zellen kann bei normalen $\mathrm{pO}_{2}$-Konzentrationen die aerobe Glykolyse aktivieren $[21,46,95]$. Die Aktivierung der Glykolyse-Enzyme Hexokinase (HK), Phosphofruktokinase (PFK), Pyruvatdehydrogenase-Kinase (PDK1) und des Pentose-5-Phosphat-Weges (via G6PDH und Transketolase-TKTL1) führt einerseits zu einer direkten Hemmung der OXPHOS in den Mitochondrien und andererseits, via erhöhter Pyruvatwerte, zu einer Steigerung des Hypoxia Inducible Factors (HIF1) [76, 77]. Der Letztere spielt eine Schlüsselrolle bei der verstärkten Transkription des Glukosetransporters (GLUT 1) und der Glykolyse-Enzyme als auch bei der Hemmung der Pyruvatdehydrogenase (PDH) mit Senkung der Pyruvatkonversion in Acetyl-CoA und nachfolgender Hemmung des Krebs-Zyklus bzw. der oxidativen Phosphorylierung [35, 102]. HIF1 aktiviert außerdem die Carboanhydrase CA9 in Tumorzellen und unterhält somit die extrazelluläre Übersäuerung [139-141].

Die Überexpression der Glukosetransporter auf der Oberfläche der Tumorzellen sichert eine enorme Aufnahme der Glukose [95], die als Hauptenergiequelle für den Tumorstoffwechsel dient. Hierzu kann man die gängigen Gaben von Glukoseinfusionen bei Krebspatienten als kontraindiziert betrachten. 


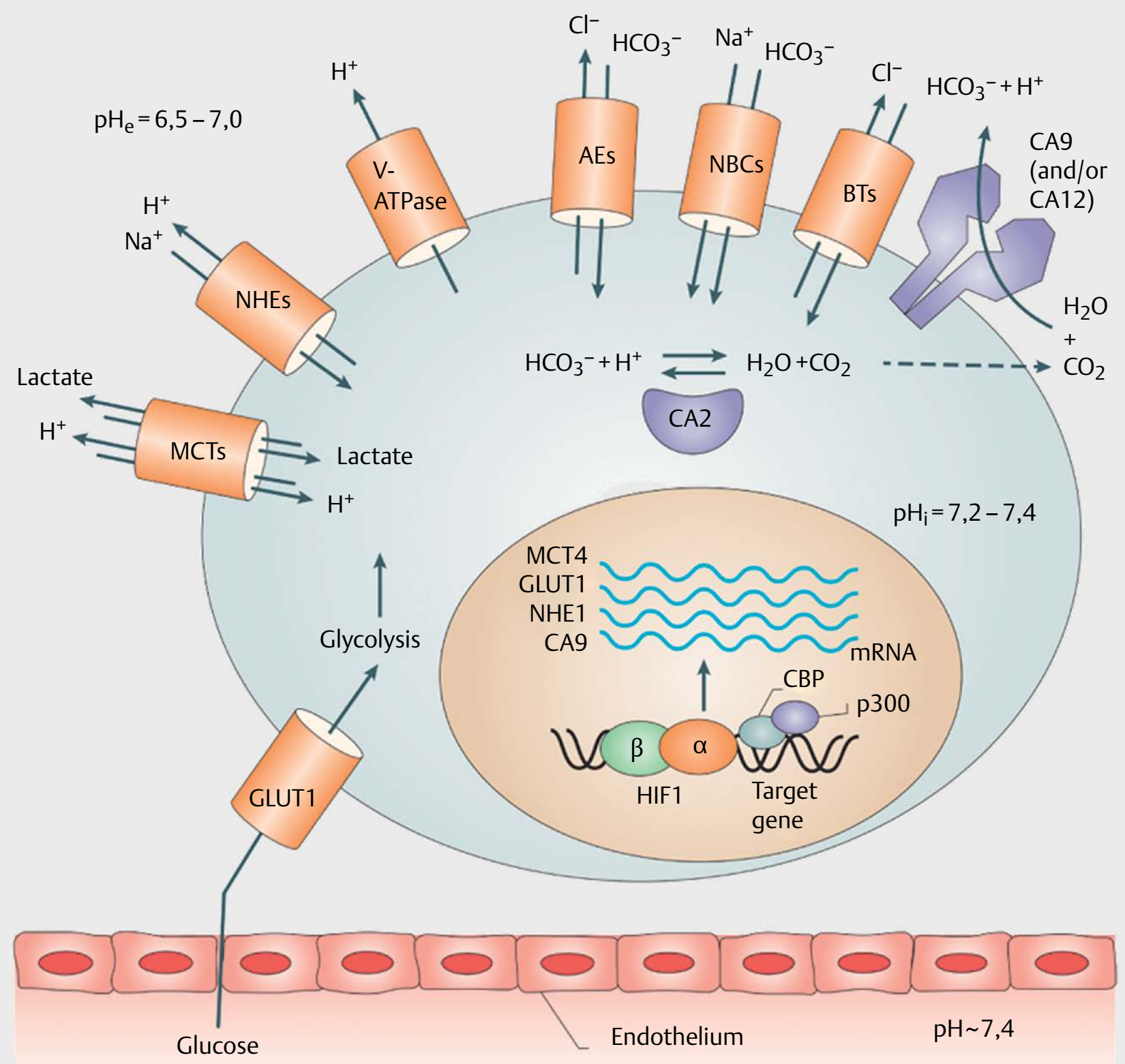

- Abb. 3 Wichtige Regulationssysteme der pH- und Redoxprozesse in der Tumorzelle. MCT: Monocarboxylat-Transporter, welcher Laktat und andere Monocarbonsäuren aus den Zellen herausdiffundieren lässt; NHE: Na ${ }^{+} \mathrm{H}^{+}$Austauscher; V-ATPase: Vakuoläre ATPase; AEs: Anionaustauscher; NBCs: $\mathrm{Na}^{+} / \mathrm{HCO}_{3}{ }^{-}$Cotransporter; CA: Carboanhydrasen; GLUT1: Glukosetransporter, überexprimiert in den meisten bösartigen Tumoren. Der intrazelluläre pH-Wert (pHi) ist leicht basisch (pHi 7,2-7,4), während der extrazelluläre pH (pHe) leicht säuerlich ist (pHe 6,5-7,0). Der Hypoxie-induzierte Faktor (HIF1) ist in Krebszellen überexprimiert und führt zur Überexpression vieler anderer Gene. CBP: CREB Protein; p300: Histon-Acetyltransferase p300. Nachdruck aus [95] mit Genehmigung der Macmillan Publishers Ltd.

\section{Stoffwechselorientierte Therapieansätze bei Krebspatienten}

Angesichts der bereits erwähnten genetischen Variabilität der Krebszellen innerhalb eines Tumors und der damit verbundenen Therapieresistenz gewinnen die o.g. toxikologischen und molekularbiologischen Grundmerkmale eine besondere Bedeutung für neue komplementäre Behandlungsansätze. In-vitro- und In-vivoStudien der letzten Jahre sowie unsere eigenen Therapieerfahrun- gen zeigen eine signifikante antiproliferative und pro-apoptotische Wirkung in Tumoren durch:

\section{Hochdosiertes Vitamin C}

Hochdosiertes Vitamin C wirkt in Anwesenheit erhöhter zellulärer Metallkonzentrationen via ROS-Bildung stark pro-oxidativ $[52,55,58]$. Andererseits kann die erhöhte Schwermetallkonzentration in verschiedenen Tumoren für therapeutische Ansätze mit Vitamin C oder Phenolen genutzt werden, wie bereits berichtet 
Redox cycle and catabolic pathways of ascorbic acid
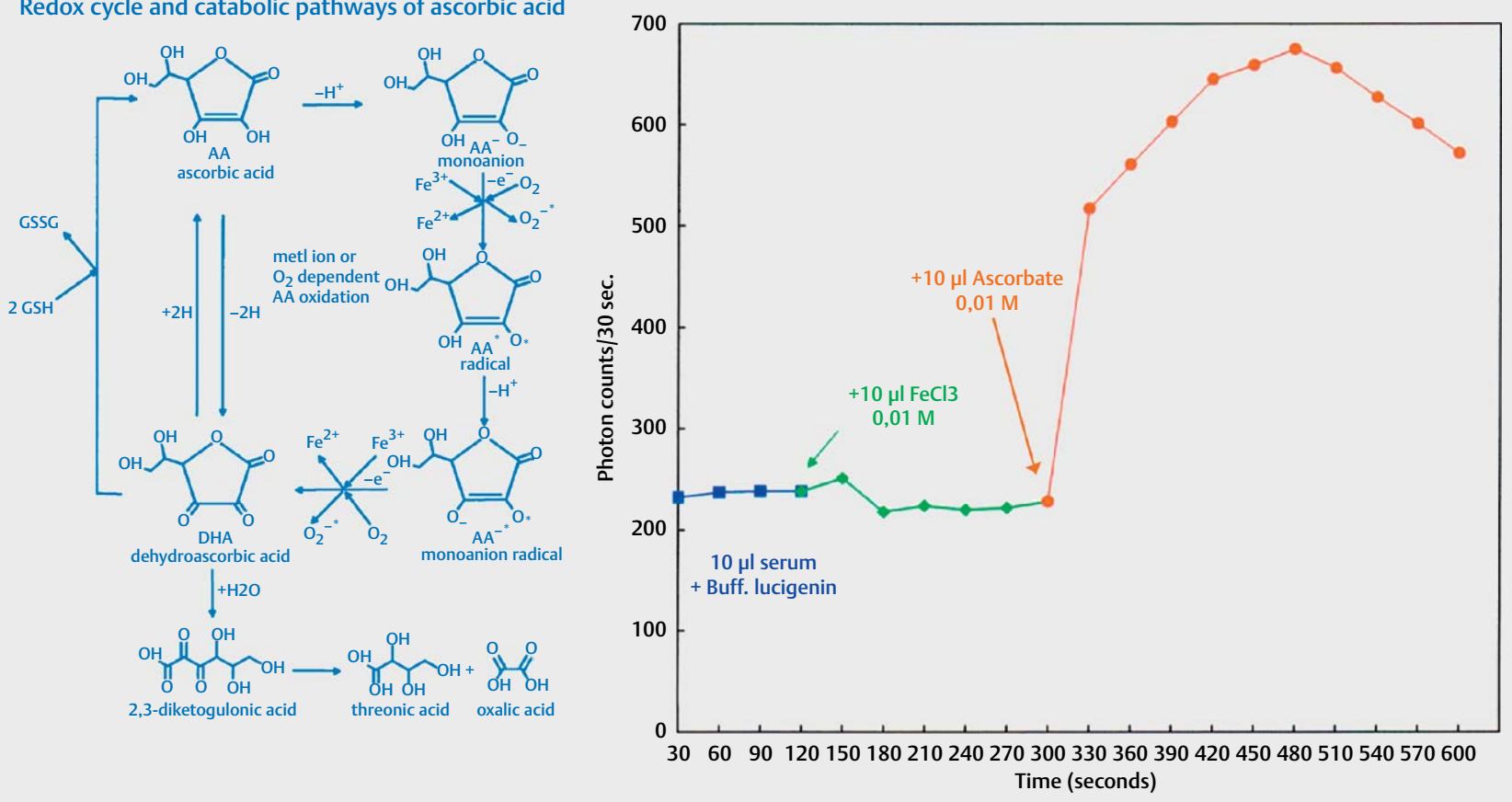

Abb. $4 \mathrm{Fe}^{3+}$ wird nur durch Zugabe von Vitamin $\mathrm{C}$ zu Fe${ }^{2+}$ reduziert, mit Entstehung von Superoxid und Wasserstoffperoxid, was in einem Chemilumineszenz-Test gut nachweisbar ist [52].
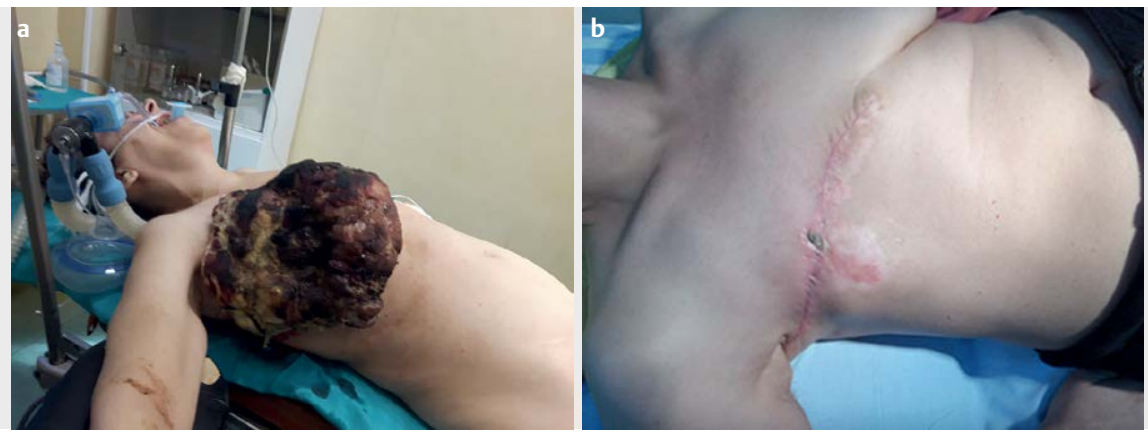

Abb. 5 Metastasiertes Mamma-CA vor (links) bzw. 8 Wochen nach OP und integrativen Therapiemaßnahmen (rechts). Patientin: VNM, 59 Jahre (vgl. auch > Tab. 2).

wurde $[9,54,74]$. Die Reduktion und Mobilisation von Übergangsmetallen aus ihren Speicher- oder Transportproteinen macht sie extrem reaktiv für die Katalyse freier Radikalreaktionen nach den Gleichungen in > Abb. 4.

Die beschriebenen Fenton- und Haber-Weiss-Reaktionen > Abb. 2 erzeugen in hohem Maß Hydroxylradikale, was zu Lipidperoxidation, Unterbrechungen der DNA-Stränge und Apoptose führen kann $[9,85,99]$. Die Autooxidation von Vitamin C mit Erzeugung von Superoxid und Wasserstoffperoxid in Anwesenheit von Übergangsmetallen wie Eisen, Nickel, Chrom oder Quecksilber kann eindeutig nachgewiesen werden mithilfe einer Chemolumineszenz-Methode im humanen Serum ( $\triangleright$ Abb. 4). In säuerlichem Milieu $\left(\mathrm{H}^{+}\right.$ Überschuss im extrazellulären Raum) wird das Superoxidradikal in $\mathrm{H}_{2} \mathrm{O}_{2}$ umgewandelt und kann die Apoptose/Nekrose der Tumorzellen induzieren.
Aufgrund der hochsignifikanten Akkumulation von Schwermetallen im Tumorgewebe haben wir erstmalig den o.g. Mechanismus als Erklärung für die prooxidative, tumorspezifische Aktivität des Vitamin C beschrieben [52, 53, 55, 58]. Dagegen werden gesunde, nicht metallbelastete Zellen, durch Vitamin C antioxidativ geschützt [19, 20, 38, 101]. Klinische Studien und eigene Erfahrungen mit pharmakologisch signifikanten Konzentrationen von Vitamin C i.v. dokumentieren eindrucksvoll die Tumorschrumpfung sowie die Verlängerung der Lebensdauer bzw. Steigerung der Lebensqualität der Patienten ( $\triangleright$ Abb. 5)

\section{Natürliche Polyphenole}

Es gibt natürliche Polyphenole, die in Anwesenheit erhöhter zellulärer Metallkonzentrationen bzw. aktivierter NADPH:Quinon Oxidoreduktasen via Superoxid- und Semiquinonradikale stark prooxi- 
a

Redoxpotential der Mischung ABDE I

( $E^{\prime}$ in $\mathrm{mV}$ ) vor und nach Metallzugabe

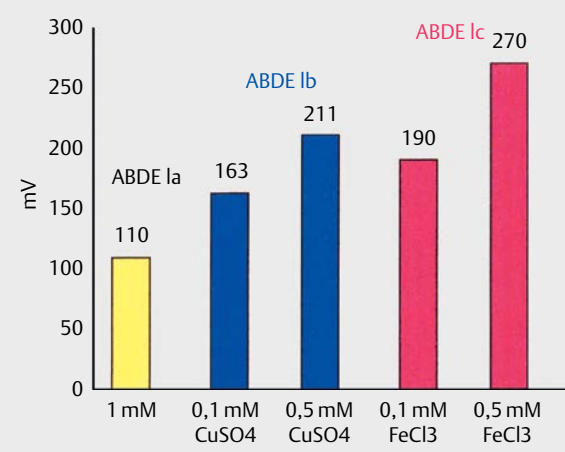

Redoxpotential der Mischung ABDE II ( $E$ ' in $\mathrm{mV}$ ) vor und nach Metallzugabe

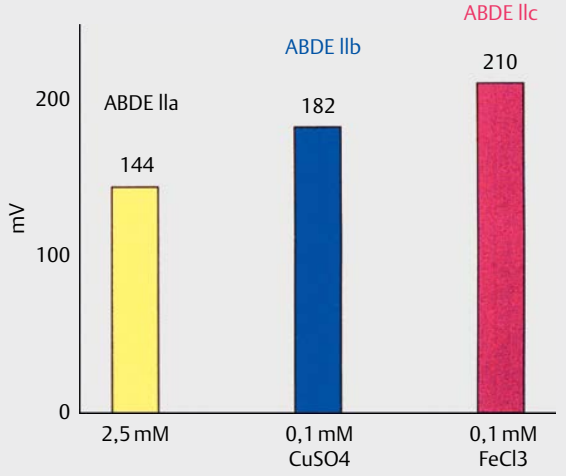

Abb. 6 Substituierte Phenole können in Anwesenheit von $\mathrm{Cu}^{2+}$ oder $\mathrm{Fe}^{3+}$ prooxidativ wirken [55].

dativ wirken $[10,55]$. Die Bioaktivierung von Phenolen in der Tumorzelle kann zu einer signifikanten Erzeugung von Superoxid-, $\mathrm{H}_{2} \mathrm{O}_{2}$ und Semiquinon-Radikalen mit schädlicher Wirkung auf die metallreichen malignen Zellen führen [107, 116]. Wie früher gezeigt, verhalten sich Polyphenolmischungen in Anwesenheit von Schwermetallen prooxidativ, mit Autooxidation zu SemiquinonRadikalen, Bildung von Superoxid und Wasserstoffperoxid, verbunden mit einer hochsignifikanten Steigerung des Redoxpotentials in situ ( $\triangleright$ Abb. 6) [55]. Die antitumorale Wirkung der phenol- und quinonhaltigen Therapeutika basiert weitgehend auf der Aktivität der Mikrosomalen NADPH:Quinon-Oxidoreduktase, welche in verschiedenen Tumorarten stark exprimiert ist und solche Therapeutika in einen tumorselektiven Art bioaktiviert [107, 116]. Die natürlichen Polyphenole verdanken ihre antitumorale Aktivität dem gleichen prooxidativen Mechanismus [4, 55, 154]. Aktuelle Studien weisen auf eine signifikante antitumorale Aktivität des Curcumins in humanen Gliom-Implantaten hin, begleitet von einer Hemmung der Angiogenese und einer deutlichen Verlängerung der Überlebensspanne [106]. In Kombination mit Chemotherapeutika wie Cisplatin oder Docetaxel wurde in Mausmodellen von Kopf- und Hals- bzw. Ovarialkarzinomen eine Hemmung der Tumorwachstumsrate bis zu $96 \%$ erreicht $[27,72]$.

\section{Ausschaltung der intrazellulären Redose}

Ein weiterer Therapieansatz ist die Ausschaltung der intrazellulären Redose mithilfe pro-oxidativer Verfahren wie Hyperthermie [51] und kurzem Fasten (3-5 Tage) [14, 69] bzw. ketogener Diät $[1,111,155]$ und regelmäßiger körperlicher Bewegung [133].

In Krebsmodellen mit Mäusen führten Kurzfasten-Zyklen zu einem gleichwertigen intratumoralen Glukoseverbrauch und Hemmung des Tumorwachstums wie bei der Behandlung mit Oxaliplatin [14]. Weiterhin führten 48-stündige Fastenzyklen in transplantierten Glioma zu signifikanten Senkungen der Blutzucker- und IGF1-Werte im Blut, gepaart mit einer erhöhten Sensibilisierung gegenüber Radio- und Chemotherapie [121].

In weiteren Tierexperimenten konnte gezeigt werden, dass die Assoziation einer ketogenen Diät mit Radiotherapie zu einer kom- pletten Remission der implantierten Tumoren führte, welche auch 200 Tage nach Absetzung der ketogenen Diät zu verzeichnen war [1]. Eine für die Epilepsiebehandlung entwickelte ketogene Fertignahrung (KetoCal), verabreicht bei Mäusen mit malignem Astrozytom oder Gliom, konnte das Wachstum und die Vaskularisierung der Tumoren bis zu 65 \% verringern und die Überlebensrate der Tiere deutlich erhöhen [139].

Erste klinische Studien bei Patienten mit fortgeschrittenen Krebserkrankungen zeigen, dass eine ketogene Diät mit Insulinhemmendem Effekt als sicher einzustufen ist und dass die erreichte Ketonkörper-Werte positiv mit der Stabilisierung der Erkrankung oder sogar mit einer Teilremission korrelieren [36].

\section{Basische Lösungen}

Der Einsatz basischer Lösungen wie Ringer-Laktat oder $\mathrm{NaHCO}_{3}$ zur Pufferung der extrazellulären Azidose zeigt antiphlogistische und metastasenhemmende Wirkung [33, 110, 115]. In diesem Sinne zeigt die alleinige Anwendung von Bikarbonat eine selektive Steigerung der Tumoren-pH, verbunden mit einer gleichzeitigen Senkung der Bildung spontaner Brustkrebs-Metastasen (> Abb. 5) sowie eine signifikante Verbesserung der Therapiewirksamkeit des Doxorubicins in Mausmodellen [110].

\section{Protonenpumpen-Inhibitoren}

Der Einsatz von Protonenpumpen-Inhibitoren aus der OmeprazolFamilie $[32,75]$ führt in verschiedenen Mausmodellen des B-ZellLymphoms zu einer deutlichen Verlangsamung des Tumorwachstums [88] und die Inzidenz der Oesophageal-Adenokarzinome bei Patienten mit Barret's Oesophagus sinkt signifikant [23]. Auch V-ATPase-Inhibitoren wie die Macrolidantibiotika Bafilomycin A und Concanamycin A führen zu einer ähnlichen Ansäuerung des intrazellulären Tumormillieus und zur Apoptose [98, 105]. Dies wurde auch in klinischen Studien bestätigt: Brustkrebspatienten, die Esomeprazol vor der Chemotherapie bekommen haben, zeigten eine fast doppelte progressionsfreie Überlebenszeit in Vergleich mit der StandardChemotherapie-Gruppe (10,7 vs 5,8 Monate) [146]. 


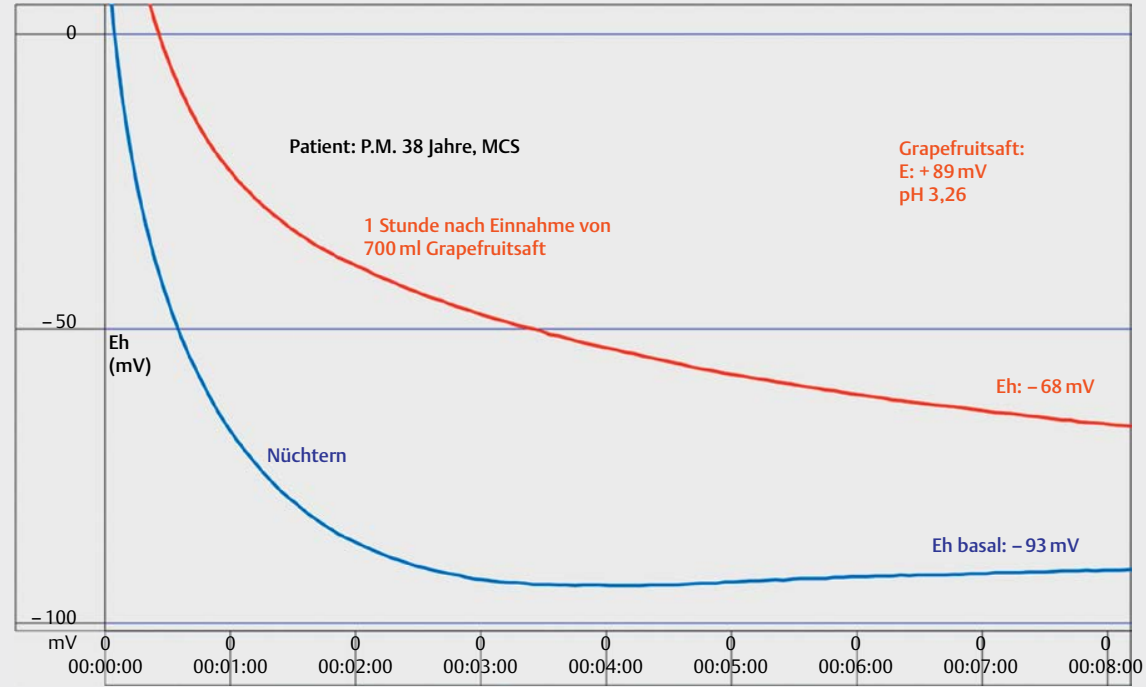

Abb. 7 Pro-oxidative Redoxverschiebung in venösem Blut, nach Einnahme (in vivo) von $700 \mathrm{ml}$ Grapefruitsaft.

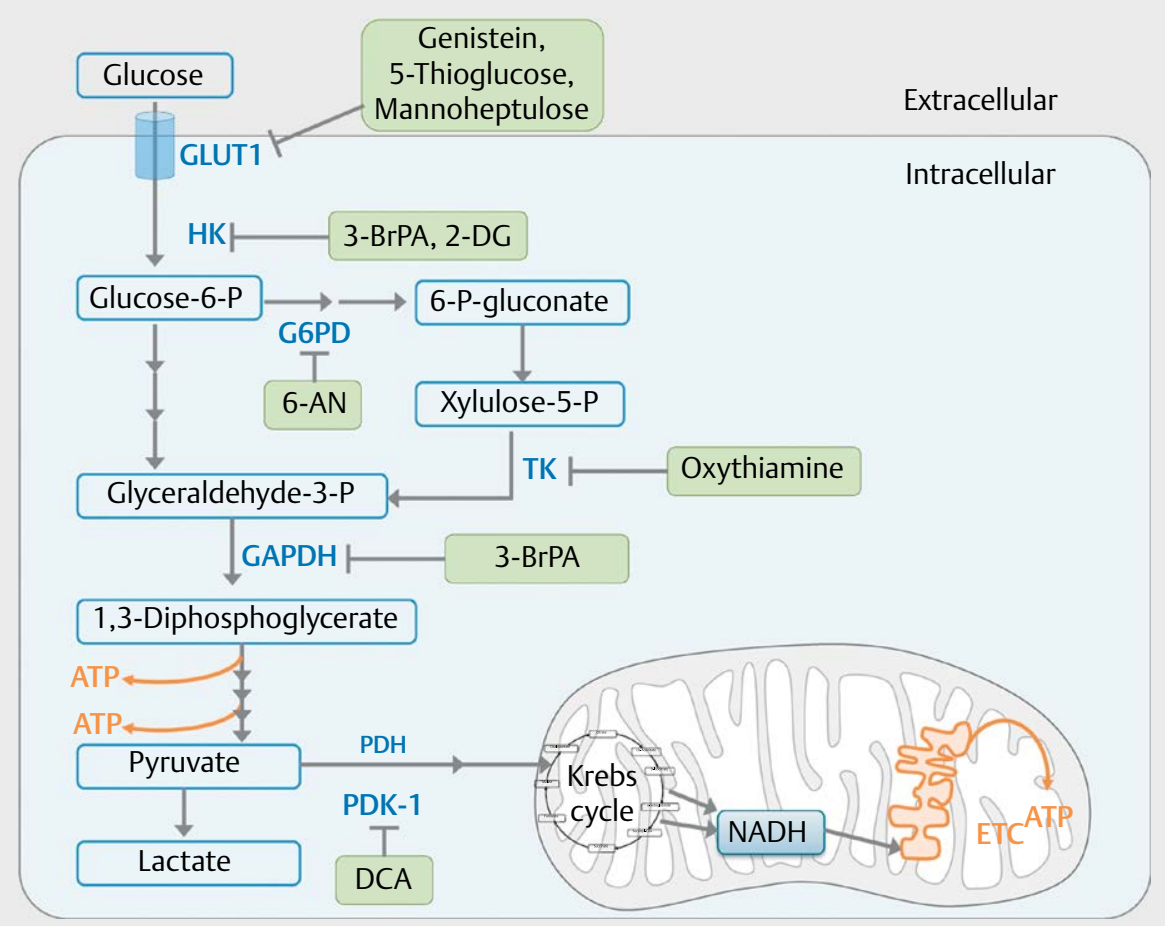

Abb. 8 Inhibitoren der Glykolyse, des Pentose-5-Phosphat-Weges und des GLUT1 in der integrativen Krebstherapie.

\section{Hemmung des $\mathrm{Na}^{+} / \mathrm{H}^{+}$Antiport Systems und der Carboanhydrase}

Die Hemmung des $\mathrm{Na}^{+} / \mathrm{H}^{+}$Antiport Systems (NHE1) führt zu intrazellulärer pHi-Senkung und Apoptose-Induktion via 5-HMA u. a. Amilorid-Derivate in Leukemia- und Hepatokarzinomazellen $[47,67,83,113]$. Interessant ist auch die Carboanhydrase (CA)Hemmung via Acetazolamiden [3], Sulphonamiden [139, 140], Cumarinen, Thiocumarinen oder Hydroxyzimtsäuren [80, 81]. Die
Hemmung der CA-IX mit dem monoklonalen Antikörper WX-G250 zusätzlich zu einem niedrigdosierten IFN-gamma-Protokoll führte in einer klinischen Studie mit metastatischen Nierenkarzinom-Patienten zu einer $79 \%$ igen Überlebensrate nach 2 Jahre im Vergleich mit der $30 \%$ igen Überlebensrate in der Gruppe, die die WX-G250 Infusionen abgesetzt bekommen hat [132]. 


\section{Ernährungsform mit niedrigem glykämischen Index}

Eine Ernährungsform mit niedrigem glykämischen Index scheint geeignet, das Tumorwachstum nicht zu fördern:

- arm an Zucker, Mehlprodukten, Zink, Eisen, Nickel, Chrom, Folsäure, Alkohol, Glutamin, Fettperoxiden u.a. [25, 84, 86, 93, 100, 130]

- reich an Omega-3-Fettsäuren, Vitamin D3, Carotinoiden, komplexen Kohlenhydraten, hochdosierten Enzympräparaten, Pflanzeneiweißen, Aminosäurekomplexen, Sphingolipiden, Phytosterolen, Isoflavonoiden, Polyphenolen $[8,15,41,44,78], \mathrm{L}+$ Milchsäure sowie pro-oxidative Gemüse- und Fruchtsäfte ( $\triangleright$ Abb. 7 ) etc.

\section{Hemmung der aeroben Glykolyse}

Die Hemmung der aeroben Glykolyse mithilfe spezifischer Inhibitoren der Hexokinase (Londiamine, 2-Deoxyglukose, 3-Brom-Pyruvat), der G6PDH (6-Aminonicotinamid), der Transketolase TKTL1 (Oxythiamin), der PDK-1 (Dichloracetat), der Glyceraldehydphosphat-Dehydrogenase (Clorohydrin, Ornidazole, Arsenat) und der Laktatdehydrogenase-A (Anti-RNS) bzw. der Glukosetransporters (GLUT1-3) via Genistein, 5-Thioglukose und Mannoheptulose kann ein Therapieansatz sein ( $\mathbf{A b b}$. 8) [53, 57, 64, 87, 125].

Seit kurzem erlauben neue Methoden die Zählung bzw. die Testung der Genexpression und der Chemosensitivität zirkulierender Tumorzellen (CTC). Deren Isolierung mithilfe monoklonaler Antikörper gegen Tumorepitopen liefert Informationen über die Eigenschaften mehrerer Tumorzentren (primär und Metastasen) und bietet eine effektive Hilfe zur Auswahl einer personalisierten Therapie $[22,118]$.

\section{Schlussbetrachtung}

Die Krebszellen weisen eine hohe genetische Variabilität innerhalb des gleichen Tumors und damit eine entsprechende Therapieresistenz gegenüber klassischen Mitteln wie Chemo- und Radiotherapien auf.

Da die Redox-, pH- und Glykolyse-Verschiebungen im Tumorgewebe als Stoffwechselmarker aller Krebszellen gelten, eignen sie sich deshalb als neue Therapieziele in der modernen Onkologie.

Die hier erwähnten neuen Behandlungsansätze, per se oder in Kombination mit klassischen onkologischen Therapien, können zu einer erheblichen Erhöhung der Lebenserwartung und -qualität führen. Eine detaillierte Beschreibung der o.g. Strategien wird in einer anderen Arbeit veröffentlicht.

\section{Danksagung}

Die Verfasser bedanken sich bei Dr. Alexandru Constantinescu für seine wertvollen Hinweise bei der Vorbereitung des Manuskriptes.

Interessenkonflikt

Die Autoren geben an, dass kein Interessenkonflikt besteht.
[1] Abdelwahab MG, Fenton KE, Preul MC et al. The ketogenic diet is an effective adjuvant to radiation therapy for the treatment of malignant glioma. PLoS One 2012; 7: e36197. doi:10.1371/journal. pone. 0036197

[2] Adachi S, Takemoto K, Ohshima S et al. Metal concentrations in lung tissue of subjects suffering from lung cancer. Int Arch Occup Environ Health 1991; 63: 193-197

[3] Ahlskog JK, Dumelin CE, Trüssel S et al. In vivo targeting of tumorassociated carbonic anhydrases using acetazolamide derivatives. Bioorg Med Chem Lett 2009; 19: 4851-4856. doi:10.1016/j. bmcl.2009.06.022

[4] Ahmad A, Syed FA, Singh S, Hadi SM. Prooxidant activity of resveratrol in the presence of copper ions: Mutagenicity in plasmid DNA. Toxicol Lett 2005; 159: 1-12. doi:10.1016/j.toxlet.2005. 04.001

[5] Akesson A, Julin B, Wolk A. Long-term dietary cadmium intake and postmenopausal endometrial cancer incidence: a population-based prospective cohort study. Cancer Res 2008; 68: 6435-6441. doi:10.1158/0008-5472.CAN-08-0329

[6] Aronson KJ, Miller AB, Woolcott CG et al. Breast adipose tissue concentrations of polychlorinated biphenyls and other organochlorines and breast cancer risk. Cancer Epidemiol Biomarkers Prev 2000; 9: 55-63

[7] Aust SD, Morehouse LA, Thomas CE. Role of metals in oxygen radical reactions. J Free Radic Biol Med 1985; 1: 3-25

[8] Awad AB, Bradford PG. Nutrition and Cancer Prevention. Boca Raton: CRC Press; 2005

[9] Baader SL, Bruchelt G, Carmine TC et al. Ascorbic-acid-mediated iron release from cellular ferritin and its relation to the formation of DNA strand breaks in neuroblastoma cells. J Cancer Res Clin Oncol 1994; 120: 415-421

[10] Babich H, Schuck AG, Weisburg JH, Zuckerbraun HL. Research strategies in the study of the pro-oxidant nature of polyphenol nutraceuticals. J Toxicol 2011; 2011: 467305. doi:10.1155/ 2011/467305

[11] Backos DS, Franklin CC, Reigan P. The role of glutathione in brain tumor drug resistance. Biochem Pharmacol 2012; 83: 1005-1012. doi:10.1016/j.bcp.2011.11.016

[12] Bauer DE, Harris MH, Plas DR et al. Cytokine stimulation of aerobic glycolysis in hematopoietic cells exceeds proliferative demand. FASEB J 2004; 18: 1303-1305. doi:10.1096/fj.03-1001fje

[13] Beyersmann D. Effects of carcinogenic metals on gene expression. Toxicol Lett 2002; 127: 63-68. doi:10.1016/S0378-4274(01)00484-2

[14] Bianchi G, Martella R, Ravera S et al. Fasting induces anti-Warburg effect that increases respiration but reduces ATP-synthesis to promote apoptosis in colon cancer models. Oncotarget 2015; 6: 11806-11819. doi:10.18632/oncotarget.3688

[15] Bougnoux P, Hajjaji N, Ferrasson MN et al. Improving outcome of chemotherapy of metastatic breast cancer by docosahexaenoic acid: a phase II trial. Br J Cancer 2009; 101: 1978-1985. doi:10.1038/sj. bjc. 6605441

[16] Brand KA, Hermfisse U. Aerobic glycolysis by proliferating cells: a protective strategy against reactive oxygen species. FASEB J 1997; 11: 388-395

[17] Buss JL, Torti FM, Torti SV. The role of iron chelation in cancer therapy. Curr Med Chem 2003; 10: 1021-1034. doi:10.2174/ 0929867033457638

Literatur 18-155 ist in der Online-Version unter www.thieme-connect.de/products verfügbar. 


\section{Ergänzendes Material}

[18] Byrne C, Divekar SD, Storchan GB et al. Metals and breast cancer. J Mammary Gland Biol Neoplasia 2013; 18: 63-73. doi:10.1007| s10911-013-9273-9

[19] Cameron E, Pauling L. Supplemental ascorbate in the supportive treatment of cancer: Prolongation of survival times in terminal human cancer. Proc Natl Acad Sci U S A 1976; 73: 3685-3689

[20] Cameron E, Pauling L. Supplemental ascorbate in the supportive treatment of cancer: reevaluation of prolongation of survival times in terminal human cancer. Proc Natl Acad Sci U S A 1978; 75: 4538-4542

[21] Cardone RA, Casavola V, Reshkin S]. The role of disturbed pH dynamics and the $\mathrm{Na}+/ \mathrm{H}+$ exchanger in metastasis. Nature Rev Cancer 2005; 5: 786-795. doi:10.1038/nrc1713

[22] Chatziioannou M, Apostolou P, Toloudi M. Circulating Tumor Cells (CTCS) as a biomarker of relapse and metastasis [Poster presentation]. Jahrestagung der Deutschen, Österreichischen und Schweizerischen Gesellschaften für Hämatologie und Onkologie 2012

[23] Cooper BT, Chapman W, Neumann CS, Gearty JC. Continuous treatment of Barrett's oesophagus patients with proton pump inhibitors up to 13 years: observations on regression and cancer incidence. Aliment Pharmacol Ther 2006; 23: 727-733. doi:10.1111/ j.1365-2036.2006.02825.x

[24] Darbre PD. Aluminium, antiperspirants and breast cancer. J Inorg Biochem 2005; 99: 1912-1919. doi:10.1016/j.jinorgbio.2005.06.001

[25] DeBerardinis RJ, Mancuso A, Daikhin E et al. Beyond aerobic glycolysis: transformed cells can engage in glutamine metabolism that exceeds the requirement for protein and nucleotide synthesis. Proc Natl Acad Sci U S A 2007; 104: 19345-19350. doi:10.1073/ pnas.0709747104

[26] Dexter DL, Leith JT. Tumor heterogeneity and drug resistance. J Clin Oncol 1986; 4: 244-257

[27] Duarte VM, Han E, Veena MS et al. Curcumin enhances the effect of cisplatin in suppression of head and neck squamous cell carcinoma via inhibition of IKK $\beta$ protein of the NFKB pathway. Mol Cancer Ther 2010; 9: 2665-2675. doi:10.1158/1535-7163.MCT-10-0064

[28] Ebadi M, Swanson S. The status of zinc, copper, and metallothionein in cancer patients. Prog Clin Biol Res 1988; 259: 161-175

[29] Ebrahim AM, Eltayeb MA, Shaat MK et al. Study of selected trace elements in cancerous and non-cancerous human breast tissues from Sudanese subjects using instrumental neutron activation analysis. Sci Total Environ 2007; 383: 52-58. doi:10.1016/j.scitotenv.2007.04.047

[30] Eldakroory SA, Morsi DE, Abdel-Rahman RH et al. Correlation between toxic organochlorine pesticides and breast cancer. Hum Exp Toxicol 2017; 36: 1326-1334. doi:10.1177/0960327116685887

[31] Elliott RL, Elliott MC, Wang F, Head JF. Breast carcinoma and the role of iron metabolism. A cytochemical, tissue culture, and ultrastructural study. Ann N Y Acad Sci 1993; 698: 159-166

[32] Fais S. Proton pump inhibitor-induced tumour cell death by inhibition of a detoxification mechanism: Symposium. J Intern Med 2010; 267: 515-525. doi:10.1111/j.1365-2796.2010.02225.x

[33] Fais $S$, Venturi G, Gatenby B. Microenvironmental acidosis in carcinogenesis and metastases: new strategies in prevention and therapy. Cancer Metastasis Rev 2014; 33: 1095-1108. doi:10.1007/ s10555-014-9531-3

[34] Fang JS, Gillies RD, Gatenby RA. Adaptation to hypoxia and acidosis in carcinogenesis and tumor progression. Semin Cancer Biol 2008; 18: 330-337. doi:10.1016/j.semcancer.2008.03.011
[35] Fantin VR, St-Pierre J, Leder P. Attenuation of LDH-A expression uncovers a link between glycolysis, mitochondrial physiology, and tumor maintenance. Cancer Cell 2006; 9: 425-434. doi:10.1016/j. ccr.2006.04.023

[36] Fine EJ, Segal-Isaacson CJ, Feinman RD et al. Targeting insulin inhibition as a metabolic therapy in advanced cancer: a pilot safety and feasibility dietary trial in 10 patients. Nutrition 2012; 28: 1028-1035. doi:10.1016/j.nut.2012.05.001

[37] Fischer K, Hoffmann P, Voelkl $S$ et al. Inhibitory effect of tumor cell-derived lactic acid on human T cells. Blood 2007; 109: 3812-3819. doi:10.1182/blood-2006-07-035972

[38] Fritz $\mathrm{H}$, Flower $\mathrm{G}$, Weeks $\mathrm{L}$ et al. Intravenous vitamin $\mathrm{C}$ and cancer: A systematic review. Integr Cancer Ther 2014; 13: 280-300. doi:10.1177/1534735414534463

[39] Fukunari H, Iwama T, Sugihara K, Miyaki M. Intratumoral heterogeneity of genetic changes in primary colorectal carcinomas with metastasis. Surg Today 2003; 33: 408-413. doi:10.1007/s10595002-2520-1

[40] Gatenby RA, Gillies RJ. Why do cancers have high aerobic glycolysis? Nature Rev Cancer 2004; 4: 891-899. doi:10.1038/nrc1478

[41] Gillet L, Roger S, Bougnoux P et al. Beneficial effects of omega-3 long-chain fatty acids in breast cancer and cardiovascular diseases: voltage-gated sodium channels as a common feature? Biochimie 2011; 93: 4-6. doi:10.1016/j.biochi.2010.02.005

[42] Gillies RJ, Raghunand N, Karczmar GS, Bhujwalla ZM. MRI of the tumor microenvironment. J Magn Reson Imaging 2002; 16: 430-450. doi:10.1002/jmri.10181

[43] Godwin AK, Meister A, O’Dwyer PJ et al. High resistance to cisplatin in human ovarian cancer cell lines is associated with marked increase of glutathione synthesis. Proc Natl Acad Sci U S A 1992; 89: 3070-3074. doi:10.1073/pnas.89.7.3070

[44] Gonzalez NJ, Isaacs LL. Evaluation of pancreatic proteolytic enzyme treatment of adenocarcinoma of the pancreas, with nutrition and detoxification support. Nutr Cancer 1999; 33: 117-124. doi:10.1207| S15327914NC330201

[45] Güttes S, Failing K, Neumann K et al. Chlororganic pesticides and polychlorinated biphenyls in breast tissue of women with benign and malignant breast disease. Arch Environ Contam Toxicol 1998; 35: 140-147. doi:10.1007/s002449900361

[46] Harguindey S, Orive G, Pedraz JL et al. The role of pH dynamics and the $\mathrm{Na}+\mathrm{H}+$ antiporter in the etiopathogenesis and treatment of cancer. Two faces of the same coin - One single nature. Biochim Biophys Acta 2005; 1756: 1-24. doi:10.1016/j.bbcan.2005.06.004

[47] Harley W, Floyd C, Dunn T et al. Dual inhibition of sodium-mediated proton and calcium efflux triggers non-apoptotic cell death in malignant gliomas. Brain Res 2010; 1363: 159-169. doi:10.1016/j. brainres.2010.09.059

[48] Hartwig A. Recent advances in metal carcinogenicity. Pure Appl Chem 2000; 72: 1007-1014

[49] Hilvo M, Baranauskiene L, Salzano AM et al. Biochemical characterization of CA IX, one of the most active carbonic anhydrase isozymes. J Biol Chem 2008; 283: 27799-27809. doi:10.1074/jbc.M800938200

[50] Husain Z, Huang Y, Seth P, Sukhatme VP. Tumor-derived lactate modifies antitumor immune response: effect on myeloid-derived suppressor cells and NK cells. J Immunol 2013; 191: 1486-1495. doi:10.4049/jimmunol.1202702 
[51] Ionescu JG. Free radical monitoring in human blood following therapy interventions with drugs and natural compounds. Médecine \& Longévité 2010; 2: 211-220

[52] Ionescu J, Poljsak B. Metal ions mediated pro-oxidative reactions with vitamin C: possible implications for treatment of different malignancies. Int J Cancer Prevention 2010; 3: 149-174

[53] Ionescu J. Die klinisch-therapeutische Relevanz der Redox-, pH- und Glukoseabbau-Verschiebungen im Tumorgewebe. Umwelt-MedizinGesellschaft 2015; 28: 86-92

[54] lonescu J. New evidence based therapies for cancer. Proceedings of the 17th Int. Symposium on Integrative Medicine, Tenerife, Spain: 2005

[55] Ionescu JG. Heavy metal accumulation in malignant tumours as basis for a new integrative therapy model. In: Klatz R, Goldman R.eds. Anti-Aging Therapeutics. Vol. IX:Boca Raton: American Academy of Anti-Aging Medicine; 2007: 189-202

[56] Ionescu JG. Klinische Relevanz der Redox- und Chemoluminiszenzbestimmungen bei Allergien, Haut- und Umwelterkrankungen. In: Marktl W, Reiter B, Ekmekcioglu C, Hrsg.. Säuren - Basen - Schlacken: Pro und Contra - eine wissenschaftliche Diskussion. Wien: Springer; 2007: 73-81

[57] Ionescu JG. Metabolic hallmarks of cancer cells as targets for specific therapies. World Congress on Biological Cancer Treatment, Frankfurt/ Main 2014;

[58] Ionescu JG, Novotny J, Stejskal V et al. Increased levels of transition metals in breast cancer tissue. Neuro Endocrinol Letters 2006; 27: (Suppl 1): 36-39

[59] Ionescu JG, Weber D, Bradford R. Applications of redox and free radical assessment in the clinical practice. International journal of Gerontology 2000; 3: 47-56

[60] Jennrich P, Schulte-Uebbing C. Einfluss toxischer Metalle auf die Krebsentstehung. Dtsche Z Onkol 2016; 48: 14-24. doi:10.1055/s $-0042-103521$

[61] Jennrich P, Schulte-Uebbing C. Löst Aluminium Brustkrebs aus? Dtsche Z Onkol 2015; 47: 4-9. doi:10.1055/s-0033-1357709

[62] Kagara N, Tanaka N, Noguchi S, Hirano T. Zinc and its transporter ZIP10 are involved in invasive behavior of breast cancer cells. Cancer Sci 2007; 98: 692-697. doi:10.1111/j.1349-7006.2007.00446.x

[63] Kemp JD, Smith KM, Kanner LJ et al. Synergistic inhibition of lymphoid tumor growth in vitro by combined treatment with the iron chelator deferoxamine and an immunoglobulin $\mathrm{G}$ monoclonal antibody against the transferrin receptor. Blood 1990; 76: 991-995

[64] Ko YH, Verhoeven HA, Lee M] et al. A translational study "case report" on the small molecule "energy blocker" 3-bromopyruvate (3BP) as a potent anticancer agent: from bench side to bedside. J Bioenerg Biomembr 2012; 44: 163-170. doi:10.1007/s10863-0129417-4

[65] Kovar J, Stunz LL, Stewart BC et al. Direct evidence that iron deprivation induces apoptosis in murine lymphoma $38 \mathrm{C} 13$. Pathobiology 1997; 65: 61-68

[66] Kroemer G, Pouyssegur ]. Tumor cell metabolism: cancer's Achilles' heel. Cancer Cell 2008; 13: 472-482. doi:10.1016/j.ccr.2008.05.005

[67] Lagarde AE, Franchi AJ, Paris S, Pouysségur JM. Effect of mutations affecting $\mathrm{Na}+: \mathrm{H}+$ antiport activity on tumorigenic potential of hamster lung fibroblasts. J Cell Biochem 1988; 36: 249-260

[68] Larrick JW, Cresswell P. Modulation of cell surface iron transferrin receptors by cellular density and state of activation. J Supramol Struct 1979; 11: 579-586. doi:10.1002/jss.400110415

[69] Lee C, Longo VD. Fasting vs dietary restriction in cellular protection and cancer treatment: from model organisms to patients. Oncogene 2011; 30: 3305-3316. doi:10.1038/onc.2011.91
[70] Lemire J, Mailloux R, Puiseux-Dao S, Appanna VD. Aluminum-induced defective mitochondrial metabolism perturbs cytoskeletal dynamics in human astrocytoma cells. J Neurosci Res 2009; 87: 1474-1483. doi:10.1002/jnr.21965

[71] Li M, Zhang Y, Liu Z et al. Aberrant expression of zinc transporter ZIP4 (SLC39A4) significantly contributes to human pancreatic cancer pathogenesis and progression. Proc Natl Acad Sci U S A 2007; 104: 18636-18641

[72] Lin YG, Kunnumakkara AB, Nair A et al. Curcumin inhibits tumor growth and angiogenesis in ovarian carcinoma by targeting the nuclear factor-kappaB pathway. Clin Cancer Res 2007; 13: 34233430. doi:10.1158/1078-0432.CCR-06-3072

[73] Liu M, Okada S. Induction of free radicals and tumors in the kidneys of Wistar rats by ferric ethylenediamine-N,N'-diacetate. Carcinogenesis 1994; 15: 2817-2821

[74] Lode HN, Bruchelt G, Zinsser D et al. Ascorbic acid induces lipid peroxidation on neuroectodermal SK-N-LO cells with high endogenous ferritin content and loaded with MAb-ferritin immunoconjugates. Anticancer Res 1994; 14 (5A): 1903-1906

[75] Low PS, Kularatne SA. Folate-targeted therapeutic and imaging agents for cancer. Curr Opin Chem Biol 2009; 13: 256-262. doi:10.1016/j.cbpa.2009.03.022

[76] Lu H, Dalgard CL, Mohyeldin A et al. Reversible inactivation of HIF-1 prolyl hydroxylases allows cell metabolism to control basal HIF-1. J Biol Chem 2005; 280: 41928-41939. doi:10.1074/jbc.M508718200

[77] Lu H, Forbes RA, Verma A. Hypoxia-inducible factor 1 activation by aerobic glycolysis implicates the Warburg effect in carcinogenesis. J Biol Chem 2002; 277: 23111-23115. doi:10.1074/jbc.M202487200

[78] Luca-Moretti M. The properties of Master Amino Acid Pattern (MAP) and its special advances in cancer therapy. World Congress on Biological Cancer Treatment, Frankfurt/Main 2014;

[79] Lusini L, Tripodi SA, Rossi R et al. Altered glutathione anti-oxidant metabolism during tumor progression in human renal-cell carcinoma. Int J Cancer 2001; 91: 55-59

[80] Maresca A, Temperini C, Pochet L et al. Deciphering the mechanism of carbonic anhydrase inhibition with coumarins and thiocoumarins. J Med Chem 2010; 53: 335-344. doi:10.1021/jm901287j

[81] Maresca A, Temperini C, Vu H et al. Non-zinc mediated inhibition of carbonic anhydrases: Coumarins are a new class of suicide inhibitors. J Am Chem Soc 2009; 131: 3057-3062. doi:10.1021/ja809683v

[82] Martin MB, Reiter R, Pham T et al. Estrogen-like activity of metals in Mcf-7 breast cancer cells. Endocrinology 2003; 144: 2425-2436. doi:10.1210/en.2002-221054

[83] Masereel B, Pochet L, Laeckmann D. An overview of inhibitors of $\mathrm{Na}+/ \mathrm{H}+$ exchanger. Eur J Med Chem 2003; 38: 547-554. doi:10.1016/50223-5234(03)00100-4

[84] McQuitty JT, DeWys WD, Monaco L et al. Inhibition of tumor growth by dietary zinc deficiency. Cancer Res 1970; 30: 1387-1390

[85] Mello Filho AC, Meneghini R. In vivo formation of single-strand breaks in DNA by hydrogen peroxide is mediated by the Haber-Weiss reaction. Biochim Biophys Acta 1984; 781: 56-63

[86] Meyerhardt JA, Sato K, Niedzwiecki D et al. Dietary glycemic load and cancer recurrence and survival in patients with stage III colon cancer: findings from CALGB 89803. J Nat Cancer Inst 2012; 104: 17021711. doi:10.1093/jnci/djs399

[87] Michelakis ED, Sutendra G, Dromparis P et al. Metabolic modulation of glioblastoma with dichloroacetate. Sci Transl Med 2010; 2: 31ra34. doi:10.1126/scitranslmed.3000677

[88] De Milito A, lessi E, Logozzi M, Lozupone F, Spada M, Marino ML et al. Proton pump inhibitors induce apoptosis of human B-cell tumors through a caspase-independent mechanism involving reactive oxygen species. Cancer Res 2007; 67: 5408-5417. doi:10.1158/0008-5472.CAN-06-4095 
[89] Millos ], Costas-Rodríguez M, Lavilla I, Bendicho C. Multielemental determination in breast cancerous and non-cancerous biopsies by inductively coupled plasma-mass spectrometry following small volume microwave-assisted digestion. Analytica Chim Acta 2008; 622: 77-84. doi:10.1016/j.aca.2008.05.066

[90] Millos ], Costas-Rodríguez M, Lavilla I, Bendicho C. Multiple small volume microwave-assisted digestions using conventional equipment for multielemental analysis of human breast biopsies by inductively coupled plasma optical emission spectrometry. Talanta 2009; 77: 1490-1496. doi:10.1016/j.talanta.2008.09.033

[91] Mills BJ, Broghamer WL, Higgins PJ, Lindeman RD. Inhibition of tumor growth by zinc depletion of rats. J Nutr 1984; 114: 746-752

[92] Minotti G, Aust SD. The requirement for iron (III) in the initiation of lipid peroxidation by iron (II) and hydrogen peroxide. J Biol Chem 1987; 262: 1098-1104

[93] El Mjiyad N, Caro-Maldonado A, Ramírez-Peinado S, Muñoz-Pinedo C. Sugar-free approaches to cancer cell killing. Oncogene 2011; 30: 253-264. doi:10.1038/onc.2010.466

[94] Morgan PE, Pastoreková S, Stuart-Tilley AK et al. Interactions of transmembrane carbonic anhydrase, CAIX, with bicarbonate transporters. Am J Physiol Cell Physiol 2007; 293: C738-C748. doi:10.1152/ajpcell.00157.2007

[95] Neri D, Supuran CT. Interfering with $\mathrm{pH}$ regulation in tumours as a therapeutic strategy. Nature Rev Drug Discov 2011; 10: 767-777

[96] Ng KH, Bradley DA, Looi LM. Elevated trace element concentrations in malignant breast tissues. Br J Radiol 1997; 70: 375-382. doi:10.1259/bjr.70.832.9166074

[97] Ohmori T, Okada K, Tabei R, Shibata T. Effects on tumor induction, growth, metastasis and histology of concurrent administration of putrescine and its metabolizing inhibitor alpha-difluoromethylornithine in nickel tumorigenesis in soft tissue. Carcinogenesis 1994; 15: 647-652

[98] Ohta T, Arakawa H, Futagami F et al. Bafilomycin A1 induces apoptosis in the human pancreatic cancer cell line Capan-1. J Pathol 1998; 185: 324-330. doi:10.1002/(SICI)1096-9896(199807)185: $3<324:$ :AID-PATH72>3.0.CO;2-9

[99] Okada S. Iron-induced tissue damage and cancer: the role of reactive oxygen species-free radicals. Pathol Int 1996; 46: 311-332

[100] Ozer U. The role of Iron on breast cancer stem-like cells. Cell Mol Biol (Noisy-Le-Grand) 2016; 62: 25-30

[101] Padayatty SJ, Riordan HD, Hewitt SM et al. Intravenously administered vitamin C as cancer therapy: three cases. CMAJ 2006; 174: 937-942. doi:10.1503/cmaj.050346

[102] Papandreou I, Cairns RA, Fontana L et al. HIF-1 mediates adaptation to hypoxia by actively downregulating mitochondrial oxygen consumption. Cell Metabol 2006; 3: 187-197. doi:10.1016/j. cmet.2006.01.012

[103] Pedersen PL. Warburg, me and Hexokinase 2: Multiple discoveries of key molecular events underlying one of cancers' most common phenotypes, the "Warburg Effect", i. e., elevated glycolysis in the presence of oxygen. J Bioenerg Biomembr 2007; 39: 211-222. doi:10.1007/s10863-007-9094-X

[104] Perera FP, Mooney LA, Stampfer M et al. Associations between carcinogen-DNA damage, glutathione S-transferase genotypes, and risk of lung cancer in the prospective Physicians' Health Cohort Study. Carcinogenesis 2002; 23: 1641-1646

[105] Pérez-Sayáns M, Somoza-Martín JM, Barros-Angueira F et al. V-ATPase inhibitors and implication in cancer treatment. Cancer Treat Rev 2009; 35: 707-713. doi:10.1016/j.ctrv.2009.08.003

[106] Perry MC, Demeule M, Régina A et al. Curcumin inhibits tumor growth and angiogenesis in glioblastoma xenografts. Mol Nutr Food Res 2010; 54: 1192-1201. doi:10.1002/mnfr.200900277
[107] Phillips RM, Naylor MA, Jaffar M et al. Bioreductive activation of a series of indolequinones by human DT-diaphorase: structure-activity relationships. J Med Chem 1999; 42: 4071-4080

[108] Pitha J, Kociolek K, Apffel CA. Opposite effects of dextrans substituted with sulfhydryls or mercury on tumor growth. Cancer Res 1979; 39: $170-173$

[109] Pouysségur ], Dayan F, Mazure NM. Hypoxia signalling in cancer and approaches to enforce tumour regression. Nature 2006; 441: 437-443. doi:10.1038/nature04871

[110] Raghunand N, He X, van Sluis R et al. Enhancement of chemotherapy by manipulation of tumour $\mathrm{pH}$. Br J Cancer 1999; 80: 1005-1011. doi:10.1038/sj.bjc.6690455

[111] Reinwald H. Ketogenic diet with MAP in cancer: new chances in tumor cachexia. World Congress on Biological Cancer Treatment, Frankfurt/Main 2014;

[112] Reshkin S], Bellizzi A, Caldeira S et al. $\mathrm{Na}+/ \mathrm{H}+$ exchanger-dependent intracellular alkalinization is an early event in malignant transformation and plays an essential role in the development of subsequent transformation-associated phenotypes. FASEB J 2000; 14: 21852197. doi:10.1096/fj.00-0029com

[113] Rich IN, Worthington-White D, Garden OA, Musk P. Apoptosis of leukemic cells accompanies reduction in intracellular $\mathrm{pH}$ after targeted inhibition of the $\mathrm{Na}(+) / \mathrm{H}(+)$ exchanger. Blood 2000; 95: 1427-1434

[114] Richardson DR. Potential of iron chelators as effective antiproliferative agents. Can J Physiol Pharmacol 1997; 75: 1164-1180

[115] Robey IF, Baggett BK, Kirkpatrick ND et al. Bicarbonate increases tumor $\mathrm{pH}$ and inhibits spontaneous metastases. Cancer Res 2009; 69: 2260-2268. doi:10.1158/0008-5472.CAN-07-5575

[116] Ross D, Traver RD, Siegel D et al. A polymorphism in NAD(P) $\mathrm{H}$ :quinone oxidoreductase (NQO1): relationship of a homozygous mutation at position 609 of the NQO1 cDNA to NQO1 activity. $\mathrm{Br}$ J Cancer 1996; 74: 995-996

[117] van Rossum JP, Schamhart DH. Oxidation-reduction (redox) potentiometry in blood in geriatric conditions: a pilot study. Exp Gerontol 1991; 26: 37-43

[118] Rudiger N, Stein EL, Schill E et al. Chemosensitivity testing of circulating epithelial tumor cells (CETC) in vitro: Correlation to in vivo sensitivity and clinical outcome. J Cancer Ther 2013; 4: 597-605. doi:10.4236/jct.2013.42077

[119] Rundle A, Tang D, Zhou J et al. The association between glutathione S-transferase M1 genotype and polycyclic aromatic hydrocarbonDNA adducts in breast tissue. Cancer Epidemiol Biomarkers Prev 2000; 9: 1079-1085

[120] Russo A, Carmichael ], Friedman N et al. The roles of intracellular glutathione in antineoplastic chemotherapy. Int J Radiat Oncol Biol Phys 1986; 12: 1347-1354. doi:10.1016/0360-3016(86)90169-0

[121] Safdie F, Brandhorst S, Wei M et al. Fasting enhances the response of glioma to chemo- and radiotherapy. PLoS One 2012; 7: e44603. doi:10.1371/journal.pone.0044603

[122] Sanchez M, Torres JV, Tormos C et al. Impairment of antioxidant enzymes, lipid peroxidation and 8-oxo-2'-deoxyguanosine in advanced epithelial ovarian carcinoma of a Spanish community. Cancer Lett 2006; 233: 28-35. doi:10.1016/j.canlet.2005.02.036

[123] Scarpa M, Stevanato R, Viglino P, Rigo A. Superoxide ion as active intermediate in the autoxidation of ascorbate by molecular oxygen. Effect of superoxide dismutase. J Biol Chem 1983; 258: 6695-6697

[124] Schafer FQ, Buettner GR. Redox environment of the cell as viewed through the redox state of the glutathione disulfide/glutathione couple. Free Radical Biol Med 2001; 30: 1191-1212. doi:10.1016/ S0891-5849(01)00480-4 
[125] Schilling F. Metabolic tumor typing - a crucial analysis for therapy strategy. World Congress on Biological Cancer Treatment, Frankfurt/ Main 2014

[126] Schulte-Uebbing C, Jennrich P, Gerhard I et al. Toxikologische, endokrinologische und immunologische Effekte Endokriner Disruptoren (ED) und dadurch verbundene Risiken für hormonabhängige Tumoren am Beispiel des Mamma- Karzinoms. Umwelt-MedizinGesellschaft 2015; 28: 37-45

[127] Schulte-Uebbing C, Jennrich P, Gerhard I et al. Prävention des Mammakarzinoms - endokrinologische und toxikologische Aspekte. Prävention und. Rehabilitation 2015; 27: 26-37

[128] Schulte-Uebbing C, Zahn V, Spechter A, Gerhard I. Schwermetalle und Aluminium als mögliche Ursachen des Mamma- Karzinoms? Signifikante Unterschiede an Metall-Konzentrationen zwischen benignem und malignem Brustgewebe. In: Schulte-Uebbing C. Angewandte Umweltmedizin. Stuttgart: Sonntag; 1996

[129] Searles Nielsen S, McKean-Cowdin R, Farin FM et al. Childhood brain tumors, residential insecticide exposure, and pesticide metabolism genes. Environ Health Perspect 2010; 118: 144-149. doi:10.1289/ ehp.0901226

[130] Selby JV, Friedman GD. Epidemiologic evidence of an association between body iron stores and risk of cancer. Int J Cancer 1988; 41: 677-682

[131] Shapiro HM. Redox balance in the body: an approach to quantitation. J Surg Res 1972; 13: 138-152. doi:10.1016/0022-4804(72)90057-1

[132] Siebels M, Rohrmann K, Oberneder R et al. A clinical phase I/II trial with the monoclonal antibody cG250 (RENCAREX $®$ ) and interferonalpha-2a in metastatic renal cell carcinoma patients. World J Urol 2011; 29: 121-126. doi:10.1007/s00345-010-0570-2

[133] Siegmund-Schultze N. Sport ist so wichtig wie ein Krebsmedikament. Dtsch Ärtzebl 2009; 106: 444-447

[134] Singh J, Carlisle DL, Pritchard DE, Patierno SR. Chromium-induced genotoxicity and apoptosis: relationship to chromium carcinogenesis (review). Oncol Rep 1998; 5: 1307-1318

[135] Sonveaux P, Végran F, Schroeder T et al. Targeting lactate-fueled respiration selectively kills hypoxic tumor cells in mice. J Clin Invest 2008; 118: 3930-3942. doi:10.1172/JCl36843

[136] Sowah D, Casey JR. An intramolecular transport metabolon: fusion of carbonic anhydrase II to the $\mathrm{COOH}$ terminus of the $\mathrm{Cl}(-) / \mathrm{HCO}(3)(-)$ exchanger, AE1. Am J Physiol Cell Physiol 2011; 301: C336-C346. doi:10.1152/ajpcell.00005.2011

[137] Spugnini EP, Citro G, Fais S. Proton pump inhibitors as anti vacuolarATPases drugs: a novel anticancer strategy. J Exp Clin Cancer Res 2010; 29: 44. doi:10.1186/1756-9966-29-44

[138] Strumylaite L, Bogusevicius A, Abdrachmanovas O et al. Cadmium concentration in biological media of breast cancer patients. Breast Cancer Res Treat 2011; 125: 511-517. doi:10.1007/s10549-0101007-8

[139] Supuran CT. Carbonic anhydrases: novel therapeutic applications for inhibitors and activators. Nature Rev Drug Discov 2008; 7: 168-181. doi:10.1038/nrd2467
[140] Supuran CT. Carbonic anhydrase inhibitors. Bioorg Med Chem Lett 2010; 20: 3467-3474. doi:10.1016/j.bmcl.2010.05.009

[141] Švastová E, Hulíková A, Rafajová M et al. Hypoxia activates the capacity of tumor-associated carbonic anhydrase IX to acidify extracellular pH. FEBS Lett 2004; 577: 439-445. doi:10.1016/j. febslet.2004.10.043

[142] Takeda A, Goto K, Okada S. Zinc depletion suppresses tumor growth in mice. Biol Trace Elem Res 1997; 59: 23-29. doi:10.1007| BF02783226

[143] Taylor KM, Morgan HE, Smart K et al. The emerging role of the LIV-1 subfamily of zinc transporters in breast cancer. Mol Med 2007; 13: 396-406

[144] Valko M, Izakovic M, Mazur M et al. Role of oxygen radicals in DNA damage and cancer incidence. Mol Cell Biochem 2004; 266: 37-56. doi:10.1023/B:MCBI.0000049134.69131.89

[145] Waalkes MP, Coogan TP, Barter RA. Toxicological principles of metal carcinogenesis with special emphasis on cadmium. Crit Rev Toxicol 1992; 22: 175-201. doi:10.3109/10408449209145323

[146] Wang BY, Zhang J, Wang JL et al. Intermittent high dose proton pump inhibitor enhances the antitumor effects of chemotherapy in metastatic breast cancer. J Exp Clin Cancer Res 2015; 34: 85. doi:10.1186/s13046-015-0194-x

[147] Wang M, Dhingra K, Hittelman WN et al. Lipid peroxidation-induced putative malondialdehyde-DNA adducts in human breast tissues. Cancer Epidemiol Biomarkers Prev 1996; 5: 705-710

[148] Wang T, Marquardt C, Foker J. Aerobic glycolysis during lymphocyte proliferation. Nature 1976; 261: 702-705. doi:10.1038/261702a0

[149] Warburg O. On the origin of cancer cells. Science 1956; 123 : 309-314. doi:10.1126/science.123.3191.309

[150] Weinberg ED. The role of iron in cancer. Eur ] Cancer Prev 1996; 5 : 19-36

[151] WHO. Fact sheet No. 297: Cancer 2015 http://www.who.int/ mediacentre/factsheets/fs297/en/ accessed April 8, 2015

[152] Yaman M, Atici D, Bakirdere S, Akdeniz I. Comparison of trace metal concentrations in malign and benign human prostate. J Med Chem 2005; 48: 630-634. doi:10.1021/jm0494568

[153] Yeh CC, Hou MF, Wu SH et al. A study of glutathione status in the blood and tissues of patients with breast cancer. Cell Biochem Funct 2006; 24: 555-559. doi:10.1002/cbf.1275

[154] Yoshino M, Haneda M, Naruse M et al. Prooxidant activity of curcumin: Copper-dependent formation of 8-hydroxy-2'deoxyguanosine in DNA and induction of apoptotic cell death. Toxicol in Vitro 2004; 18: 783-789. doi:10.1016/j.tiv.2004.03.009

[155] Zhou W, Mukherjee P, Kiebish MA et al. The calorically restricted ketogenic diet, an effective alternative therapy for malignant brain cancer. Nutr Metab (Lond) 2007; 4: 5. doi:10.1186/1743-7075-4-5 